\title{
Ocean-Atmosphere Dynamical Coupling Fundamental to the Atlantic Multidecadal Oscillation
}

\author{
Robert C. J. Wills, Kyle C. Armour, David S. Battisti, And Dennis L. Hartmann \\ Department of Atmospheric Sciences, University of Washington, Seattle, Washington
}

(Manuscript received 30 April 2018, in final form 17 September 2018)

\begin{abstract}
The North Atlantic has shown large multidecadal temperature shifts during the twentieth century. There is ongoing debate about whether this variability arises primarily through the influence of atmospheric internal variability, through changes in ocean circulation, or as a response to anthropogenic forcing. This study isolates the mechanisms driving Atlantic sea surface temperature variability on multidecadal time scales by using lowfrequency component analysis (LFCA) to separate the influences of high-frequency variability, multidecadal variability, and long-term global warming. This analysis objectively identifies the North Atlantic subpolar gyre as the dominant region of Atlantic multidecadal variability. In unforced control runs of coupled climate models, warm subpolar temperatures are associated with a strengthened Atlantic meridional overturning circulation (AMOC) and anomalous local heat fluxes from the ocean into the atmosphere. Atmospheric variability plays a role in the intensification and subsequent weakening of ocean overturning and helps to communicate warming into the tropical Atlantic. These findings suggest that dynamical coupling between atmospheric and oceanic circulations is fundamental to the Atlantic multidecadal oscillation (AMO) and motivate approaching decadal prediction with a focus on ocean circulation.
\end{abstract}

\section{Introduction}

In both observations and climate models, North Atlantic sea surface temperatures (SSTs) show spatially coherent variability at multidecadal time scales. Periods of higher-than-average SSTs are associated with warmer summers over North America and western Europe (Sutton and Hodson 2005), Arctic sea ice loss (Mahajan et al. 2011; Day et al. 2012; Zhang 2015; Yeager et al. 2015), drought in the United States (Enfield et al. 2001; McCabe et al. 2004; Nigam et al. 2011), drought relief in the Sahel (Gray 1990; Zhang and Delworth 2006), and a higher frequency of landfalling Atlantic hurricanes (Gray 1990; Goldenberg et al. 2001; Zhang and Delworth 2006). Multiple physical mechanisms have been put forth to explain this variability. Most studies have focused on the role of internal variability in ocean circulation, principally the Atlantic meridional overturning circulation (AMOC; Delworth et al. 1993; Delworth and Mann 2000; Latif et al. 2004; Knight et al. 2005; Medhaug and Furevik 2011; Wang and Zhang 2013; Zhang and Wang 2013; MacMartin et al. 2013; Ba et al. 2014; O’Reilly et al. 2016;

Corresponding author: Robert C. Jnglin Wills, rcwills@uw.edu
Kim et al. 2018). However, multidecadal temperature variability can also arise from stochastic atmospheric forcing of temperature anomalies stored in the ocean mixed layer (Hasselmann 1976; Clement et al. 2015; Cane et al. 2017). Additionally, some of the observed North Atlantic temperature variability over the twentieth century is thought to result from a response to external forcing (Booth et al. 2012; Tandon and Kushner 2015; Si and $\mathrm{Hu}$ 2017; Bellucci et al. 2017; Bellomo et al. 2018), such as from greenhouse gasses, anthropogenic and volcanic aerosols, and stratospheric ozone. Several recent studies have suggested that atmospheric teleconnections and cloud feedbacks are essential for multidecadal variability in the tropical North Atlantic (Yuan et al. 2016; Brown et al. 2016; Bellomo et al. 2016). Do these different mechanisms make up one coherent mode of variability or are they distinct mechanisms operating on different time scales and in different geographic locations?

Atlantic temperature variability is traditionally characterized by the North Atlantic SST index (NASSTI), the spatially averaged SST anomaly over the North Atlantic basin $\left(0^{\circ}-60^{\circ} \mathrm{N}, 0^{\circ}-80^{\circ} \mathrm{W}\right)$, with the influence of global warming removed through linear detrending 
(Enfield et al. 2001) or by subtracting the global-mean SST (Trenberth and Shea 2006). NASSTI appears to vary on multidecadal time scales, and is thus often lowpass filtered and referred to as the Atlantic multidecadal oscillation (AMO). Recent work has shown that the amplitude and phase of the AMO are sensitive to the method of detrending (Ting et al. 2009; Frankcombe et al. 2015). Moreover, the choice of averaging region is problematic, as no physical mechanism has been postulated that dictates that multidecadal SST variability should be coherent between the equator and $60^{\circ} \mathrm{N}$. The use of the current NASSTI/AMO index is based solely on the history of its introduction and, as we will show, mixes multidecadal temperature variability with other forms of temperature variability on shorter time scales.

Here, we seek to determine the mechanisms driving multidecadal variability of Atlantic SSTs without a priori assumptions about its spatial or temporal structure. To do so, we use low-frequency component analysis (LFCA), introduced by Wills et al. (2018; cf. Schneider and Held 2001), an objective method to find spatial anomaly patterns with the highest ratio of low-frequency to total variance. We apply this method to Atlantic SST anomalies in observations and in unforced preindustrial control simulations with comprehensive climate models. We use the results to identify the physical mechanisms that are important for unforced Atlantic multidecadal variability in climate models and develop a mechanistic understanding of the AMO. While a number of other studies have investigated the mechanisms of Atlantic multidecadal variability based on its manifestations on the subsurface ocean and sea level (Zhang 2008, 2010; Buckley et al. 2014; Zhang and Zhang 2015; Yan et al. 2018), we focus in particular on the surface manifestation of Atlantic multidecadal variability (i.e., the AMO) to address the large body of literature taking this perspective.

Section 2 describes the analysis methods, datasets, and climate model simulations used. Section 3 describes the low-frequency components of Atlantic SST variations in observations and climate models. In section 4, we discuss how LFCA provides insight into the mechanisms of unforced Atlantic multidecadal variability in climate models, and in particular how these mechanisms differ from the mechanisms of variability at shorter time scales. In section 5 , we compare different indices of Atlantic multidecadal variability and the AMO. Section 6 discusses how these results compare to recent studies using slab-ocean models. The key findings are summarized in section 7. In the appendixes, we explore how AMO variability differs across models and discuss the next-lowest-frequency mode of Atlantic SST variability.

\section{Methods}

\section{a. $L F C A$}

Low-frequency component analysis isolates the lowfrequency variability in a dataset by finding low-frequency patterns (LFPs) that are linear combinations of the leading empirical orthogonal functions (EOFs) and sorting them by the ratio of low-frequency to total variance in their corresponding time series, called low-frequency components (LFCs). We define low-frequency variance based on a lowpass filter with a cutoff at 10 years. This type of analysis can be used to find the spatial pattern that best discriminates between some type of variance representing a "signal" compared to "noise" that exists within internal variability or between realizations and has been variously called optimal filtering or signal-to-noise maximizing EOF analysis (Allen and Smith 1997; Venzke et al. 1999; Schneider and Griffies 1999; Schneider and Held 2001; Ting et al. 2009). These methods take advantage of any spatial structure of covariance in the "noise" to optimally filter it out.

To ensure that the LFPs correspond to variability that actually occurs within the dataset, the LFPs are required to be linear combinations of the $N$ leading EOFs. For an $n \times p$ spatiotemporal data matrix $\mathbf{X}$ with zero time mean (e.g., $n$ time steps of SST anomalies at $p$ grid points), we compute the EOFs $\mathbf{a}_{k}$, which are the eigenvectors of the sample covariance matrix of the unfiltered data,

$$
\mathbf{C}=(n-1)^{-1} \mathbf{X}^{\mathrm{T}} \mathbf{X} .
$$

The EOFs are normalized $\left\|\mathbf{a}_{k}\right\|=1$ such that the corresponding eigenvalues $\sigma_{k}^{2}=\mathbf{a}_{k}^{\mathrm{T}} \mathbf{C} \mathbf{a}_{k}$ give the variance associated with the $k$ th EOF and the principal components $\mathrm{PC}_{k}=\sigma_{k}^{-1} \mathbf{X} \mathbf{a}_{k}$ have unit variance. The data matrix $\mathbf{X}$ is weighted by the square root of grid cell area such that the covariance is area weighted.

We look for linear combinations of the first $N$ EOFs,

$$
\mathbf{u}_{k}=\left[\frac{\mathbf{a}_{1}}{\sigma_{1}} \frac{\mathbf{a}_{2}}{\sigma_{2}} \cdots \frac{\mathbf{a}_{N}}{\sigma_{N}}\right] \mathbf{e}_{k},
$$

such that the ratio of low-frequency to total variance,

$$
r_{k}=\frac{\left(\widetilde{\mathbf{X}} \mathbf{u}_{k}\right)^{\mathrm{T}} \widetilde{\mathbf{X}} \mathbf{u}_{k}}{\left(\mathbf{X} \mathbf{u}_{k}\right)^{\mathrm{T}} \mathbf{X} \mathbf{u}_{k}}=\frac{\mathbf{u}_{k}^{\mathrm{T}} \widetilde{\mathbf{C}} \mathbf{u}_{k}}{\mathbf{u}_{k}^{\mathrm{T}} \mathbf{C} \mathbf{u}_{k}},
$$

is maximized when the data matrix is projected onto them. The coefficient vectors $\mathbf{e}_{k}$ are normalized such that $\left\|\mathbf{e}_{k}\right\|=1$. Here, $\widetilde{\mathbf{X}}$ is the pointwise low-pass filtered spatiotemporal data matrix and $\widetilde{\mathbf{C}}$ is the covariance matrix of the low-pass filtered data,

$$
\widetilde{\mathbf{C}}=(n-1)^{-1} \widetilde{\mathbf{X}}^{\mathrm{T}} \widetilde{\mathbf{X}}
$$


We use a linear Lanczos filter with a 10-yr low-pass cutoff and reflected boundary conditions to focus on variability at decadal and longer time scales (i.e., multidecadal variability).

The normalization factors $\sigma_{k}^{-1}$ in (2) ensure that the covariance in the denominator of (3) is equal to 1 . Using (2), (3), and the definition of a principal component, we find that the coefficient vectors $\mathbf{e}_{k}$ are eigenvectors of the covariance (cov) matrix $\mathbf{R}$ of the first $N$ low-pass filtered principal components,

$$
\mathbf{R}_{i j}=\operatorname{cov}\left(\widetilde{\mathrm{PC}}_{i}, \widetilde{\mathrm{PC}}_{j}\right)
$$

The matrix $\mathbf{R}$ has $N$ eigenvectors, $\mathbf{R e}_{k}=r_{k} \mathbf{e}_{k}$. The eigenvalues $r_{k}$ give the fraction of the variance in the $k$ th mode that occurs at low frequencies. The projection of the unfiltered data onto the linear combination vectors $\mathbf{u}_{k}$ gives the low-frequency components,

$$
\mathrm{LFC}_{k}=\mathbf{X} \mathbf{u}_{k} .
$$

The regression of the unfiltered data onto the $k$ th LFC gives the $k$ th LFP,

$$
\mathbf{v}_{k}=\mathbf{X}^{\mathrm{T}} \mathrm{LFC}_{k}=\left[\begin{array}{llll}
\sigma_{1} \mathbf{a}_{1} & \sigma_{2} \mathbf{a}_{2} & \cdots & \sigma_{N} \mathbf{a}_{N}
\end{array}\right] \mathbf{e}_{k} .
$$

The LFCs are sorted by their variance ratio $r_{k}$ such that the leading LFCs describe modes of low-frequency variability. The LFPs and LFCs are analogous to EOFs and principal components, respectively, in that the LFCs have unit variance and the LFPs describe the anomaly pattern associated with a one standard deviation anomaly in the LFC.

LFCA has two parameters, the number of EOFs included $N$ and the low-pass cutoff $T$ (or more generally the properties of the filter used). Our results are insensitive to the exact values of $N$ and $T$ used, at least for $N$ between 10 and 50 and for $T>5$ years. We have limited our analysis of observed SSTs to $N<50$, because for 50 or more EOFs, the number of spatial degrees of freedom becomes comparable to the number of temporal degrees of freedom in the 10-yr low-pass filtered data, even when including observations back to 1900. A detailed discussion of the robustness of LFCA to the choice of parameters can be found in Wills et al. (2018).

While filtering is used to define the linear combination of EOFs, the resulting LFCs are unfiltered and can thus display seasonal variations and rapid transitions. Unlike principal component analysis of low-pass filtered data, LFCA uses information about spatiotemporal covariance at all time scales (e.g., in computing the EOFs $\mathbf{a}_{k}$ ). LFCA thus provides a method to isolate the regions and physical mechanisms important at long time scales while avoiding the issues with attributing lead-lag relationships based on filtered data [as discussed in Cane et al. (2017)].
TABLE 1. CMIP5 preindustrial control simulations used in this study and the 500 model years used from each. Models with MOC data are denoted with an asterisk.

\begin{tabular}{lclc}
\hline \hline \multicolumn{1}{c}{ Model } & Model years & \multicolumn{1}{c}{ Model } & Model years \\
\hline ACCESS1.0* & $300-799$ & GFDL-ESM2M* & $1-500$ \\
ACCESS1.3* & $250-749$ & GISS-E2-H & $2450-2949$ \\
BCC-CSM1.1 & $1-500$ & GISS-E2-R* & $4031-4530$ \\
BNU-ESM & $1509-2008$ & HadGEM2-ES & $1935-2434$ \\
CanESM2* & $2511-3010$ & INM-CM4.0* & $1850-2349$ \\
CCSM4* & $801-1300$ & IPSL-CM5A & $2300-2799$ \\
CESM1-BGC* & $101-600$ & MIROC5* & $2370-2869$ \\
CMCC-CMS & $3684-4183$ & MIROC-ESM & $1930-2429$ \\
CNRM-CM5* & $2200-2699$ & MPI-ESM-LR* & $2350-2849$ \\
CSIRO-Mk3.6.0 & $1-500$ & MPI-ESM-MR* & $2350-2849$ \\
FGOALS-s2 & $1851-2350$ & MPI-ESM-P* & $2506-3005$ \\
GFDL-CM3* & $1-500$ & MRI-CGCM3* & $1851-2350$ \\
GFDL-ESM2G & $1-500$ & NorESM1-M* & $701-1200$ \\
\hline
\end{tabular}

\section{b. Datasets and climate model simulations}

We analyze observed SSTs over the period 1900-2016 from the NOAA Extended Reconstructed SST (ERSST) dataset, version 3b (ERSST.v3b; Smith et al. 2008), and output from preindustrial control simulations of 26 fully coupled climate models from phase 5 of the Coupled Model Intercomparison Project (CMIP5; Taylor et al. 2012). External forcing from greenhouse gases, aerosols, ozone, and solar variability is fixed at preindustrial levels throughout the simulations. We use preindustrial control simulations to focus on understanding the mechanisms of unforced variability in Atlantic SSTs without mixing in information about forced changes, for which the mechanisms are likely different. We include 500 years from each model's control simulation, shown in Table 1 . We use model output of surface temperature (TS), sea level pressure (SLP), ocean meridional overturning streamfunction (MOC), and sensible-heat, latent-heat, and radiative fluxes contributing to the net surface heat flux (SHF). MOC data (including both msftmyz and msftyyz in the standard CMIP5 notation) are only available for a subset of the models (16 in total), as noted in Table 1. BCC-CSM1.1 and INM-CM4.0 have missing SHF data and are omitted from the analysis of net surface heat fluxes. We remove quadratic trends from all outputs of the preindustrial control simulations in order to remove the effects of model drift. However, trends are included in the ERSST analysis: Linear trends are removed before filtering but then added back into the data matrix $\widetilde{\mathbf{X}}$ such that linear trends are included in the definition of low-frequency variance.

\section{c. Data processing for CMIP5 ensemble}

All model output is interpolated to a common analysis grid. For surface fields, we use the $2^{\circ}$ grid of ERSST. For 
MOC, we use a $1^{\circ}$ grid in latitude and 52 vertical levels extending to 5250-m depth. Rather than interpolating model output of SST from the irregular ocean grids to the $2^{\circ}$ analysis grid, we use TS, which is output on each model's atmospheric grid. To obtain SST data from TS, we set all temperatures below the freezing point of seawater (where sea ice is present) to the freezing point. After interpolation, we exclude all grid points that are over land.

To apply LFCA to an ensemble of climate model simulations, we concatenate the individual model monthly SST anomaly matrices $\mathbf{X}_{i}$ into one ensemble anomaly matrix,

$$
\mathbf{X}_{E}=\left[\begin{array}{l}
\mathbf{X}_{1}^{\mathrm{T}} \mathbf{X}_{2}^{\mathrm{T}} \cdots \mathbf{X}_{n_{E}}^{\mathrm{T}}
\end{array}\right]^{\mathrm{T}}
$$

The climatological seasonal cycle is subtracted from each data matrix $\mathbf{X}_{i}$ separately such that we remove differences in climatology between models. Here, $n_{E}$ is the number of models in the CMIP5 preindustrial ensemble. In low-pass filtering the ensemble data matrix $\mathbf{X}_{E}$, we do not filter over discontinuities between models; the data from each model are filtered separately then concatenated,

$$
\widetilde{\mathbf{X}}_{E}=\left[\widetilde{\mathbf{X}}_{1}^{\mathrm{T}} \widetilde{\mathbf{X}}_{2}^{\mathrm{T}} \ldots \widetilde{\mathbf{X}}_{n_{E}}^{\mathrm{T}}\right]^{\mathrm{T}} .
$$

LFCA is then applied to find the SST anomaly pattern that maximizes the ratio of low-frequency to total variance over the entire ensemble.

When computing lead-lag regressions and correlations with the corresponding SST indices, significance levels are computed by analyzing the lag- 0 regressions or correlations with 500 phase randomized samples of each SST index, following Ebisuzaki (1997). Phase randomization is applied to the concatenated multimodel index such that it also randomizes phase across different models.

\section{Multidecadal variability of the subpolar North Atlantic}

The two leading LFPs/LFCs of monthly Atlantic SST anomalies (from the climatological seasonal cycle) between $40^{\circ} \mathrm{S}$ and $75^{\circ} \mathrm{N}$ in the observations (ERSST; Smith et al. 2008), over the period 1900-2016, correspond to basinwide long-term warming and subpolar North Atlantic multidecadal variability (Fig. 1). We retain 25 EOFs in the LFCA to capture $85 \%$ of the total Atlantic SST variance. LFC 1 is highly correlated (0.94) with global-mean SST and thus represents the impact of global warming on Atlantic SSTs. LFP 2 shows largescale warming of the North Atlantic, concentrated in the North Atlantic subpolar gyre. Its time series (LFC 2; Fig. 1c) shows a pronounced warm phase from 1924 to
1965 followed by a pronounced cold phase from 1966 to 1997 and a weaker warm phase since 1998. This agrees well with the multidecadal shifts in NASSTI (correlation of 0.74 , coherence greater than 0.85 for periods greater than 12 years), but LFC 2 has a much larger ratio of lowfrequency to total variance than does NASSTI $(r=0.76$ vs 0.55$)$. While the temperature patterns associated with LFC 2 and NASSTI are similar in the subpolar gyre (Figs. 1b,d), LFC 2 has a much weaker relationship with tropical Atlantic SSTs. Together, these results suggest that the AMO is confined to the subpolar North Atlantic, while the tropical Atlantic varies primarily on shorter (intradecadal) time scales, adding noise to the traditional NASSTI/AMO definition.

LFP/LFC 2 is similar to proposed SST-based indices of AMOC (Rahmstorf et al. 2015; Caesar et al. 2018), and similarly shows a negative trend over the twentieth century ( -0.6 standard deviations per century). However, the magnitude of negative trend in LFC 2 is sensitive to the time period analyzed. Other aspects of the results in Fig. 1 are robust across different choices of time periods and can be recovered by transferring trends between LFCs 1 and 2, as long as we include data back to 1960. [We also obtain similar results from an analysis of the Hadley Centre Sea Ice and Sea Surface Temperature dataset, version 1.1 (HadISSTv1.1; Rayner et al. 2003); LFCs 1 and 2 of HadISSTv1.1 show aspects of the longterm SST trends, and LFC 3 has a 0.75 correlation with LFC 2 of ERSST.] Time periods shorter than about 60 years contain less than one full cycle of AMO variability such that this statistical analysis mixes the AMO with the secular trend. Statistical analysis of SST anomalies cannot by itself distinguish the relative influences of external forcing and internal variability on observed Atlantic SST variability. Distinguishing forced from unforced components in observations requires a better understanding of the physical mechanisms of AMO variability, which we will develop (based on coupled climate models) in the next section.

The observational record of ocean circulation (Cunningham et al. 2007) and air-sea heat fluxes (Chou et al. 2003; Yu and Weller 2007; Berry and Kent 2009) is too short to constrain mechanisms of variability on multidecadal time scales, particularly since lead-lag relationships with the AMO are dominated by the two major AMO transitions in the observational record during 1966-68 and 1995-98. We thus turn our focus to numerical simulations with fully coupled atmosphereocean models. To identify mechanisms of unforced variability, we analyze CMIP5 preindustrial control simulations, where greenhouse gases and aerosols are kept fixed at preindustrial levels. We include 500 years from each of 26 different models such that we 
LFCA (25 EOFs, 10-year lowpass cutoff)
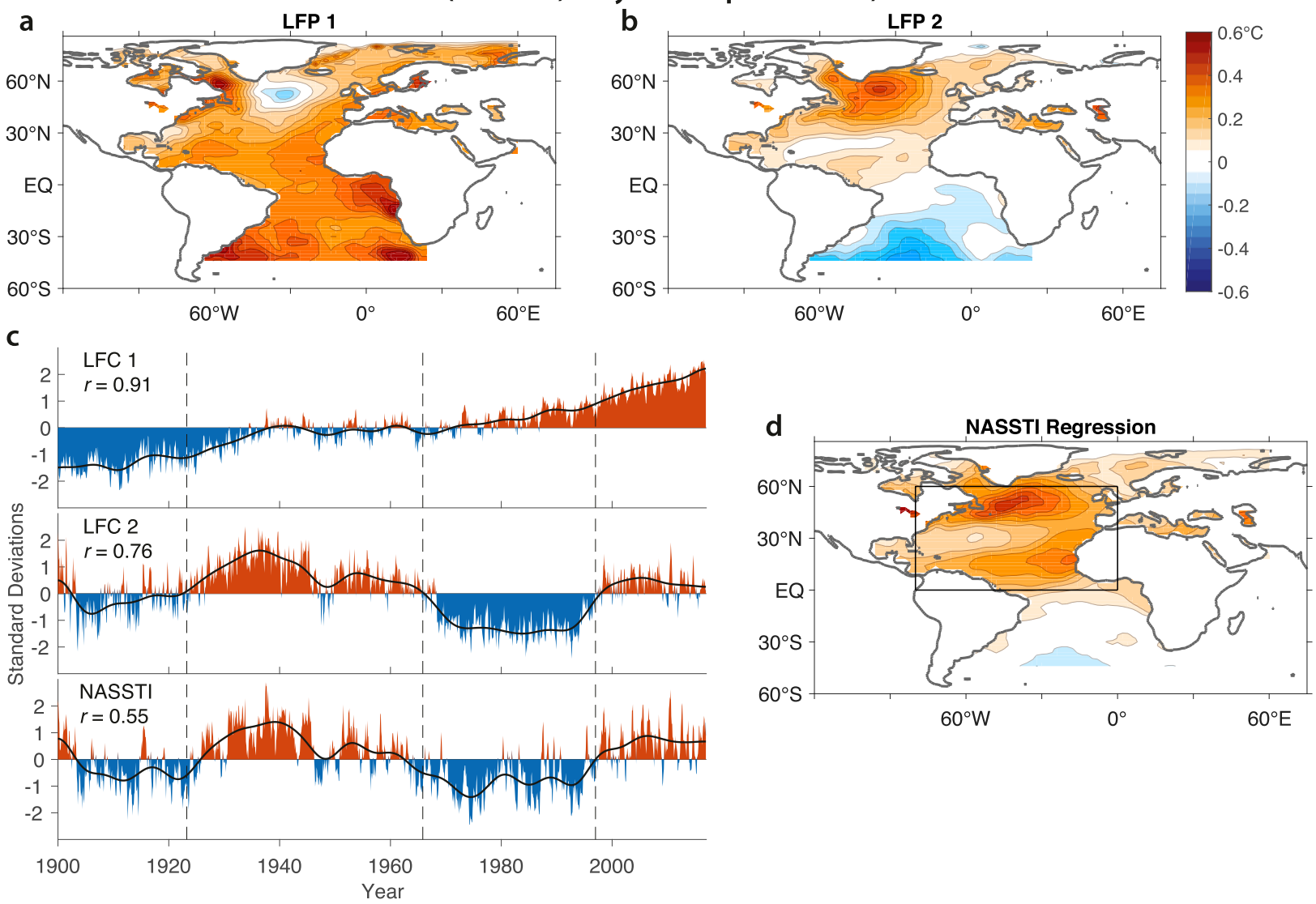

FIG. 1. Atlantic low-frequency components (LFCs) in ERSST.v3b. The (a) first and (b) second low-frequency patterns (LFPs) of Atlantic SST anomalies over the historical period from the ERSST.v3b dataset, using low-frequency component analysis (LFCA) with 25 EOFs retained and a 10-yr low-pass cutoff. (c) The first and second LFCs of Atlantic SST, which correspond to the spatial anomaly patterns in (a) and (b). The North Atlantic SST index (NASSTI), based on linearly detrended SSTs, is shown for comparison. Dashed vertical lines show years with major AMO transitions. Black lines show each index filtered with a 10-yr low-pass filter; $r$ is the ratio of low-frequency (greater than 10 years) to total variance. Note that using global-mean SST to remove the global warming signal from NASSTI further reduces its variance ratio $r$ to 0.51 without qualitatively changing its SST pattern. (d) Regression of Atlantic SST anomalies on NASSTI.

analyze a total of 13000 years of unforced variability (Table 1). To reduce the dimensionality of this large dataset, we compute the leading 50 EOFs of monthly Atlantic SST anomalies (from each model's climatological seasonal cycle with quadratic trends removed) across the entire multimodel ensemble (capturing $72 \%$ of the total variance) and input these to the LFCA. By including $50 \mathrm{EOFs}$, we include information about variability at small spatial scales (e.g., ocean frontal zones) that could not be captured by a large-scale average such as NASSTI. Rather than trying to assess which models best simulate Atlantic multidecadal variability, we focus on multimodel composites that illustrate the representative mechanisms within the ensemble.

The leading LFP of monthly Atlantic SST anomalies (between $40^{\circ} \mathrm{S}$ and $75^{\circ} \mathrm{N}$ ) in the CMIP5 preindustrial ensemble shows warming throughout the high-latitude
North Atlantic (Fig. 2a), particularly at latitudes greater than $40^{\circ} \mathrm{N}$, with the largest warming within the subpolar gyre. The corresponding LFC has considerable persistence out to decadal time scales (inset in Fig. 2a). This bears qualitative similarity with LFCA applied to individual models (appendix A), where each model emphasizes warming in a slightly different region of the subpolar North Atlantic. Compared to the pattern of low-frequency variability in ERSST (Fig. 1b), the multimodel composite SST pattern (Fig. 2a) has larger SST anomalies in the Arctic and a weaker connection with Southern Hemisphere temperatures. Averaged over the full Atlantic domain, the pattern correlation between them is 0.64 , higher than for any individual model's SST pattern associated with LFC 1 variability. This suggests that the multimodel composite is a better representation of the real world than any individual model. The decadal 
LFP 1 (50 EOFs, 10-year lowpass cutoff)

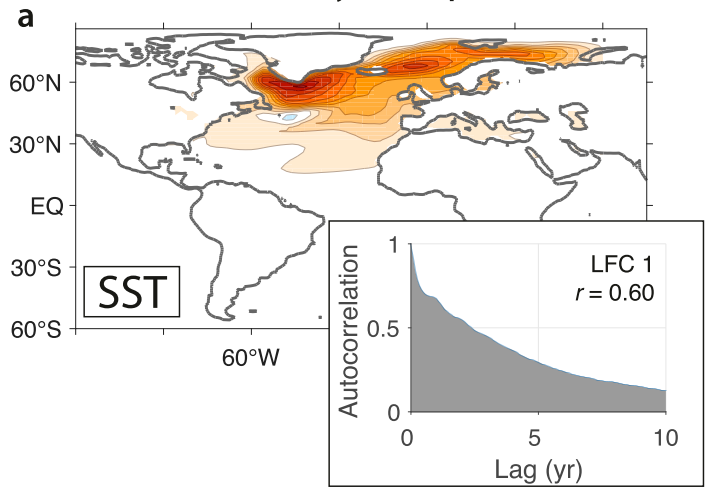

C

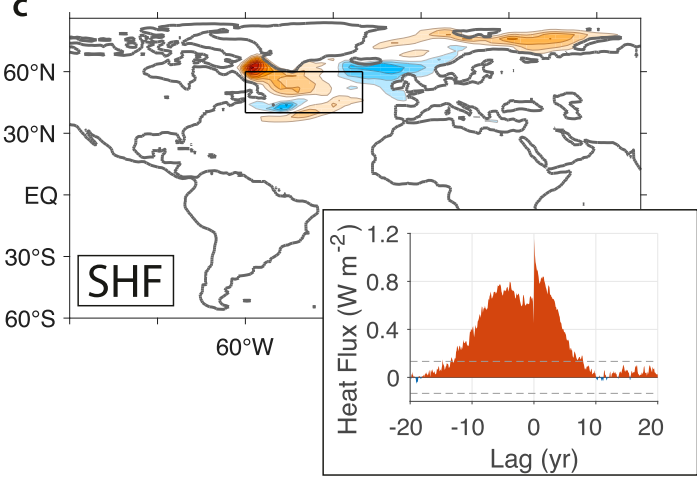

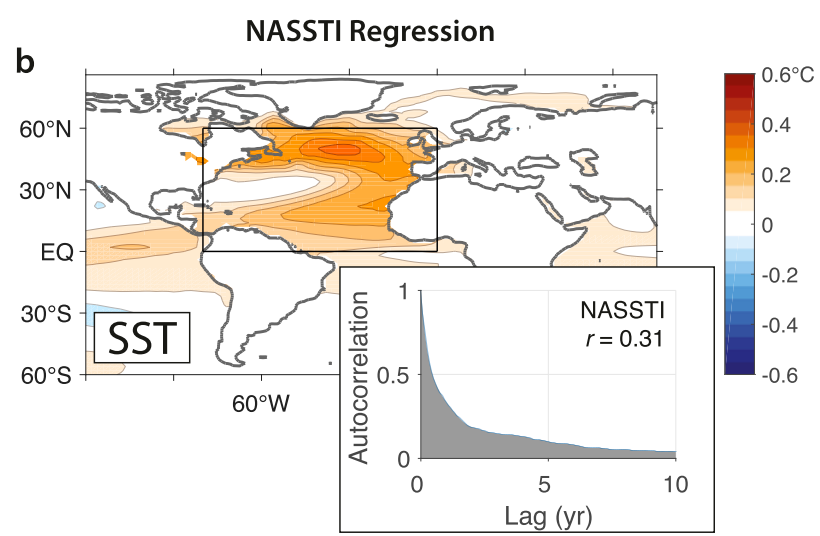

d

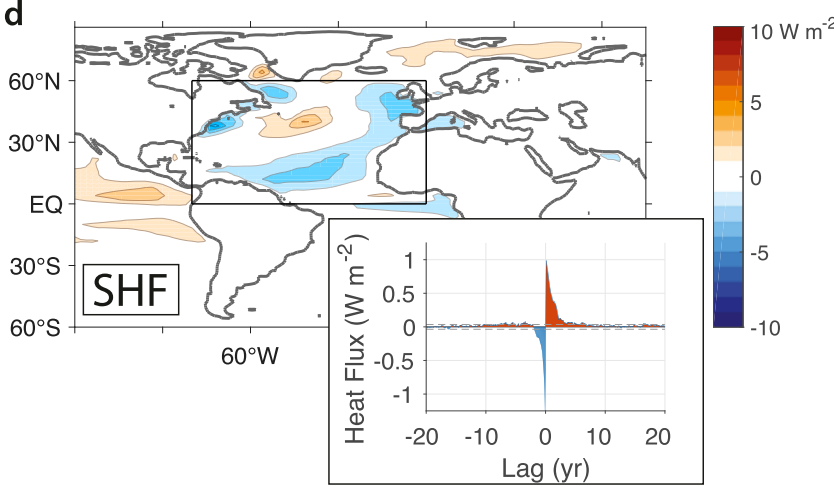

FIG. 2. Comparison of LFC 1 and NASSTI in coupled climate models. (a),(b) Spatial pattern of SST anomalies associated with a one standard deviation anomaly in LFC 1 and NASSTI, respectively, computed over the CMIP5 preindustrial ensemble; the insets show the autocorrelation of the associated indices. (c),(d) Regression of net sea surface heat flux anomalies onto LFC 1 and NASSTI, respectively. Positive values denote an anomalous heat flux from the ocean into the atmosphere. Insets show the lead-lag regression of heat flux anomalies (averaged over the box in the corresponding figure) on each index. Lag-0 is the time where the SST pattern is maximum; positive lags indicate heat flux anomalies that lag the index. Dashed gray lines give the $95 \%$ significance levels based on phase randomization. Averaging is done over all 26 CMIP5 models used in this study; see Table 1.

persistence is somewhat smaller in the CMIP5 preindustrial ensemble (LFC 1 autocorrelation $e$-folding time of 4 years) than in ERSST (LFC 2 autocorrelation $e$-folding time of 10.5 years). This corresponds to a reduced ratio of low-frequency to total variance in CMIP5 compared to ERSST ( $r=0.60$ vs 0.76$)$ and could indicate either that Atlantic multidecadal variability operates on shorter time scales in models than in observations or that external forcing contributed to the observed variations of North Atlantic SSTs over the twentieth century.

For comparison, the SST pattern associated with the traditional NASSTI/AMO definition shows a horseshoe-like warming pattern within the $0^{\circ}-60^{\circ} \mathrm{N}$ latitude range used to define it (Fig. 2b) and has markedly less persistence, similar to our findings in the observational SST data (Fig. 1). NASSTI explains $26 \%$ more of the total Atlantic SST variance than LFC 1, but 59\% less of the variance on decadal and longer time scales, owing to its lower ratio of low-frequency to total variance.
LFC 1 and NASSTI are both associated with sea ice loss and warming over Europe, eastern North America, and northwestern Africa, giving surface temperature anomalies that are locally larger than the SST anomalies (not shown; cf. Sutton and Hodson 2005; Mahajan et al. 2011). The model-derived LFC 1 and NASSTI give two representations of Atlantic SST variability that can be used to give two perspectives on the associated mechanisms, focusing in particular on how the mechanisms differ between time scales. Because these indices capture some of the same multidecadal variability (see section 5), we will refer to them both as indices of the AMO.

The second LFP of monthly Atlantic SST anomalies in the preindustrial ensemble shows a tripolar SST anomaly between the Gulf Stream, the subpolar gyre, and the Norwegian seas (see appendix B). The corresponding LFC varies on 8-20-yr time scales. In appendix B, we discuss how it could be related to subpolar gyre variability in response to wind stress forcing [as discussed in previous 
work by Curry and McCartney (2001) and Sun et al. (2015)]. Neither of the leading LFPs are sensitive to the domain or LFCA parameters used, and our analysis is broadly consistent with an analogous analyses of annual or seasonal SST anomalies. ${ }^{1}$ Moreover, we can find similar indices by applying LFCA to global, rather than Atlantic, SST anomalies (not shown).

\section{Mechanisms of ocean-atmosphere dynamic coupling within the AMO}

We use lead-lag relationships between air-sea heat flux anomalies (including sensible heat, latent heat, and radiative components) and SST anomalies to determine whether SST variability is driven by direct atmospheric forcing or by ocean circulation changes (which can result either from internal ocean variability or from prior atmospheric wind and buoyancy forcing). The lag-0 regressions of air-sea heat flux anomalies onto LFC 1 and NASSTI show striking differences (Figs. 2c,d). Positive LFC 1 anomalies are associated with anomalous net heat fluxes from the ocean into the atmosphere in the Labrador Sea, subpolar gyre, and Barents-Kara Sea (Fig. 2c)-all regions of positive SST anomalies. ${ }^{2}$ This suggests that these SST anomalies are maintained by ocean circulation changes and anomalous ocean heat transport.

Averaging heat flux anomalies over the subpolar North Atlantic, we find that the ocean is losing energy to the atmosphere for more than 10 years surrounding a maximum in LFC 1 (inset in Fig. 2c). This is only possible if anomalous ocean heat flux convergence sustains the warm temperatures, because these surface heat flux anomalies would otherwise act to cool the ocean surface. The reduction in upward heat fluxes a few years before the maximum warming and subsequent heat flux spike in the year following indicates that atmospheric heat fluxes contribute some additional warming on shorter time scales. Specifically, there is a region of the northeast Atlantic, extending from the southern coast of Iceland

\footnotetext{
${ }^{1}$ The area-weighted pattern correlation between LFP 1 of annual SST anomalies (not shown) and LFP 1 of monthly SST anomalies is 0.98 for analysis of Atlantic SST anomalies in the CMIP5 preindustrial control ensemble.

${ }^{2}$ We describe the AMO mechanisms focusing on the warm phase for clarity of explanation, but since this analysis is based on regressions on the LFC 1 index, all mechanisms apply also with opposite sign. In this way, ocean heat flux convergence contributes to the variance of SST. Note, however, that because the SST tendency due to ocean heat flux convergence is opposite in sign to the tendency due to surface heat fluxes, ocean heat flux convergence does not necessarily increase the total variance of SST compared to a slab-ocean model.
}

toward Great Britain, where the anomalous net surface heat flux is into the ocean during and in the years preceding a warm event (Figs. 2c, 3d).

In contrast, NASSTI anomalies are associated with anomalous heat fluxes from the atmosphere into the ocean throughout much of the $0^{\circ}-60^{\circ} \mathrm{N}$ latitude range (Fig. 2d). Averaged over these latitudes, heat flux anomalies are into the ocean immediately before a temperature maximum and out of the ocean immediately following, consistent with direct atmospheric forcing of this variability. The lead-lag relationships of LFC 1 and NASSTI with air-sea heat flux anomalies differ partly because these indices identify heat flux variability in different regions, but the lead-lag relationships remain qualitatively different even if consistent averaging regions are used (Fig. 3). Only LFC 1 shows anomalous heat loss from the ocean throughout warm events, an indication that SST anomalies are sustained by anomalous ocean heat flux convergence.

To investigate the ocean circulation changes associated with these two types of AMO-like variability, we regress monthly anomalies of the AMOC streamfunction onto LFC 1 and NASSTI. LFC 1 anomalies are associated with a maximum AMOC strengthening of $0.41 \mathrm{~Sv}\left(1 \mathrm{~Sv} \equiv 10^{6} \mathrm{~m}^{3} \mathrm{~s}^{-1}\right)$ per standard deviation (Fig. 4a). This AMOC anomaly extends across the equator and reinforces the climatological AMOC streamfunction. The AMOC anomaly associated with NASSTI looks markedly different, with opposite changes in the North Atlantic subtropical and subpolar gyres (Fig. 4b), indicating adjustment of the ocean gyres in response to wind and/or buoyancy forcing.

Both LFC 1 and NASSTI show an AMOC maximum 2-3 years before the maximum North Atlantic warming (Figs. 5a,c). Combined with the necessity to invoke ocean heat flux convergence to explain surface heat flux anomalies (Fig. 2c), this suggests that AMOC plays a causal role in AMO variability. The relationship with AMOC is stronger for LFC 1; the NASSTI relationship is obscured by a short-lived peak at lag-0 (Fig. $5 \mathrm{c}$ ), which corresponds to a change in the ocean gyres rather than an increase in ocean overturning. In essence, NASSTI is mixing together information about any variability that leads to warming in the North Atlantic, whether that is strengthened AMOC or a net heat flux from the atmosphere to the ocean due to stochastic atmospheric variability (the latter of which also leads to a change in the ocean gyres).

The regression of SLP anomalies also differs between LFC 1 and NASSTI. The lag-0 regression of SLP anomalies onto LFC 1 shows a low pressure anomaly centered over the region of positive subpolar SST anomalies (Fig. 4c). This atmospheric circulation anomaly acts to weaken the trade winds and communicate the warming into the tropical Atlantic (cf. Yuan et al. 2016; Brown 

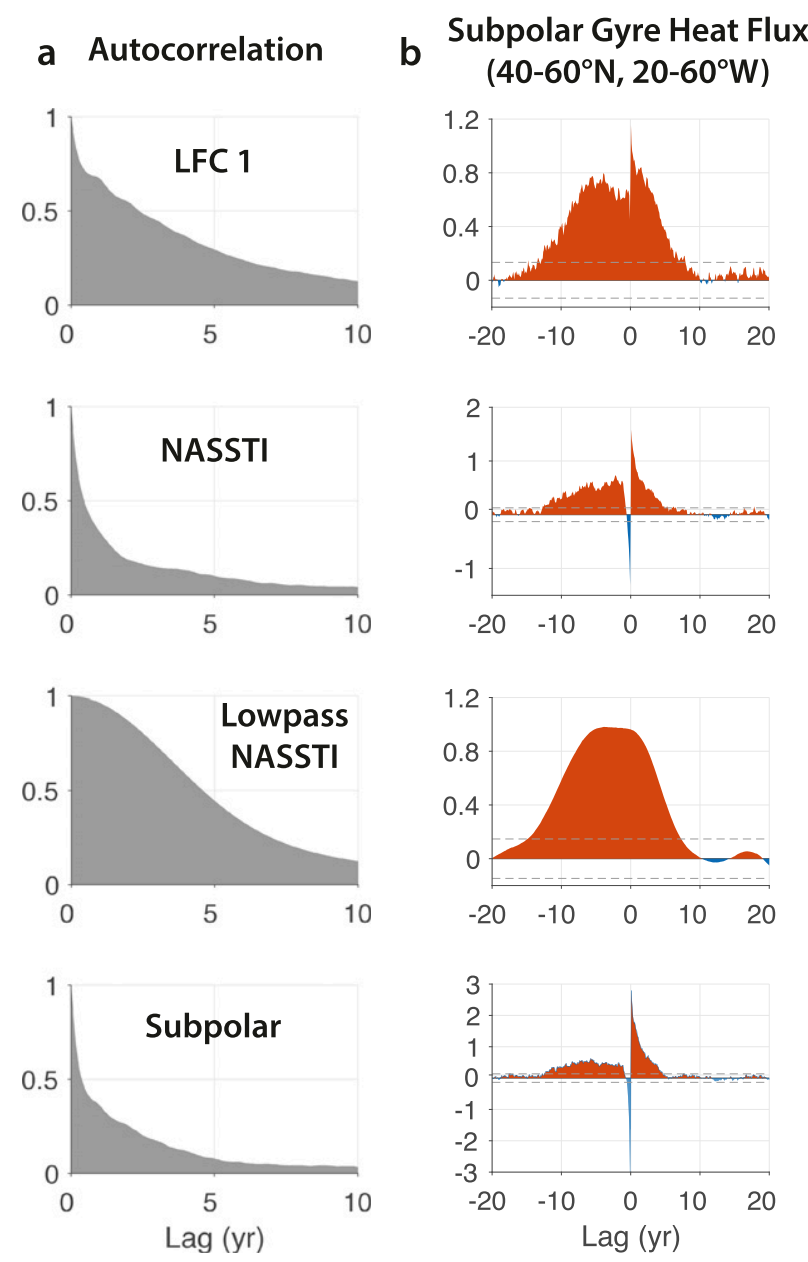
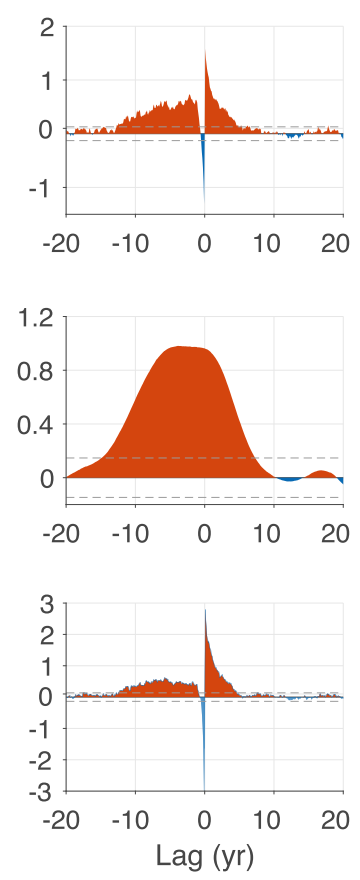
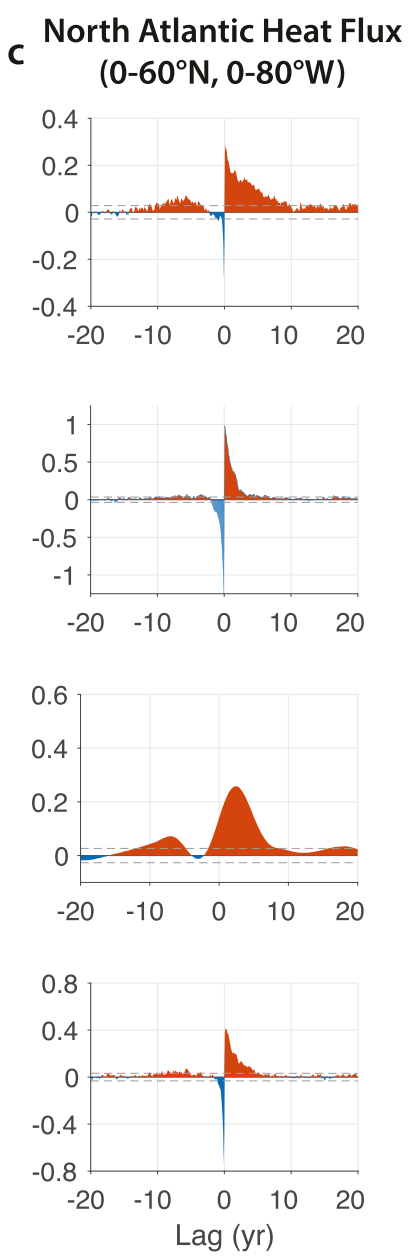

NE Atlantic Heat Flux $\left(30-65^{\circ} \mathrm{N}, 0-30^{\circ} \mathrm{W}\right)$
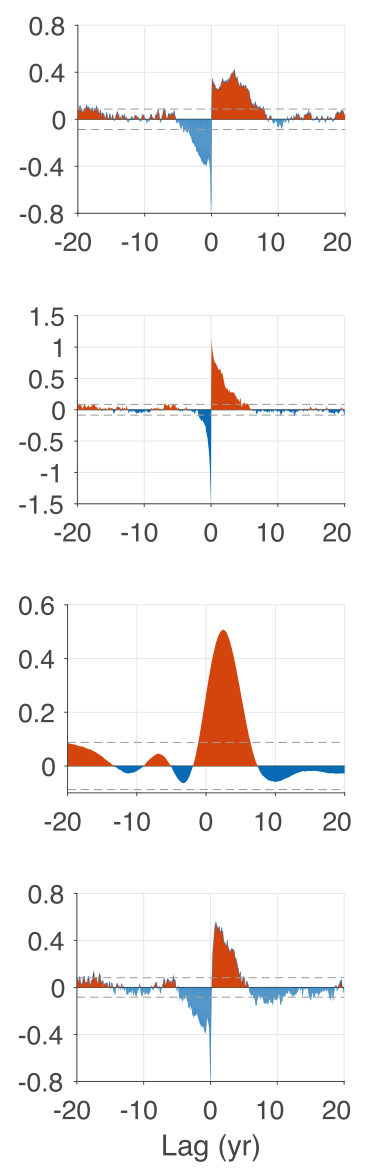

FIG. 3. Lead-lag regressions of regional air-sea heat flux anomalies on AMO indices. The (a) autocorrelation of and (b)-(d) lead-lag regression of heat flux anomalies onto LFC 1 , NASSTI, 10-yr low-pass filtered NASSTI, and the subpolar $\left(40^{\circ}-60^{\circ} \mathrm{N}, 20^{\circ}-60^{\circ} \mathrm{W}\right) \mathrm{SST}$ index. Heat flux anomalies are averaged over (b) the subpolar box shown in Fig. 2c, (c) the full North Atlantic box shown in Fig. 2d, and (d) the northeast Atlantic $\left(30^{\circ}-65^{\circ} \mathrm{N}, 0^{\circ}-30^{\circ} \mathrm{W}\right)$. The heat flux regressions in the top two rows of (b) and (c) break up the differences in heat flux regressions shown in Figs. $2 \mathrm{c}$ and $2 \mathrm{~d}$ into differences in averaging region and differences in SST index. Heat fluxes are in units of watts per square meter per standard deviation of the associated index. Lag-0 is the time where the SST pattern is maximum; positive lags indicate heat flux anomalies that lag the index. Dashed gray lines give the $95 \%$ significance levels based on phase randomization.

et al. 2016). This basinwide low pressure anomaly develops only after AMOC has reached its maximum strength (Fig. 6), suggesting that it is a response to AMOC-driven warming of the North Atlantic, either directly or indirectly. The circulation anomaly fits with what is expected from a direct atmospheric response to extratropical thermal forcing (Hoskins and Karoly 1981). The lag-0 regression of SLP anomalies on NASSTI shows a low pressure anomaly over the subtropical gyre and weak high pressure anomaly over the subpolar gyre (Fig. 4d). The weaker subtropical anticyclone weakens the trade winds, reducing evaporative cooling of the subtropics, and helping to warm subtropical SSTs (Figs. $2 \mathrm{~b}$ and $2 \mathrm{~d}$ ). Since this anomaly opposes the climatological atmospheric circulation, it acts to weaken the ocean gyres, leading to the AMOC streamfunction anomaly shown in Fig. 4b.

Variability of the North Atlantic atmospheric circulation can be characterized by the North Atlantic Oscillation (NAO; Hurrell 1995). Both LFC 1 and NASSTI show positive NAO anomalies from 12 to 2 years before peak warming (Figs. 5b,d). This is consistent with a proposed mechanism where positive NAO anomalies act to bring cold dry air off the North American continent, enhancing turbulent heat fluxes from the ocean into the atmosphere, stimulating deep-water formation in the Labrador Sea, and strengthening AMOC (Fig. 6; years -5 to -2 ; Sun et al. 2015; Delworth and Zeng 2016; Delworth et al. 2016, 2017). In the absence of an ocean circulation response, the heat flux anomalies associated 

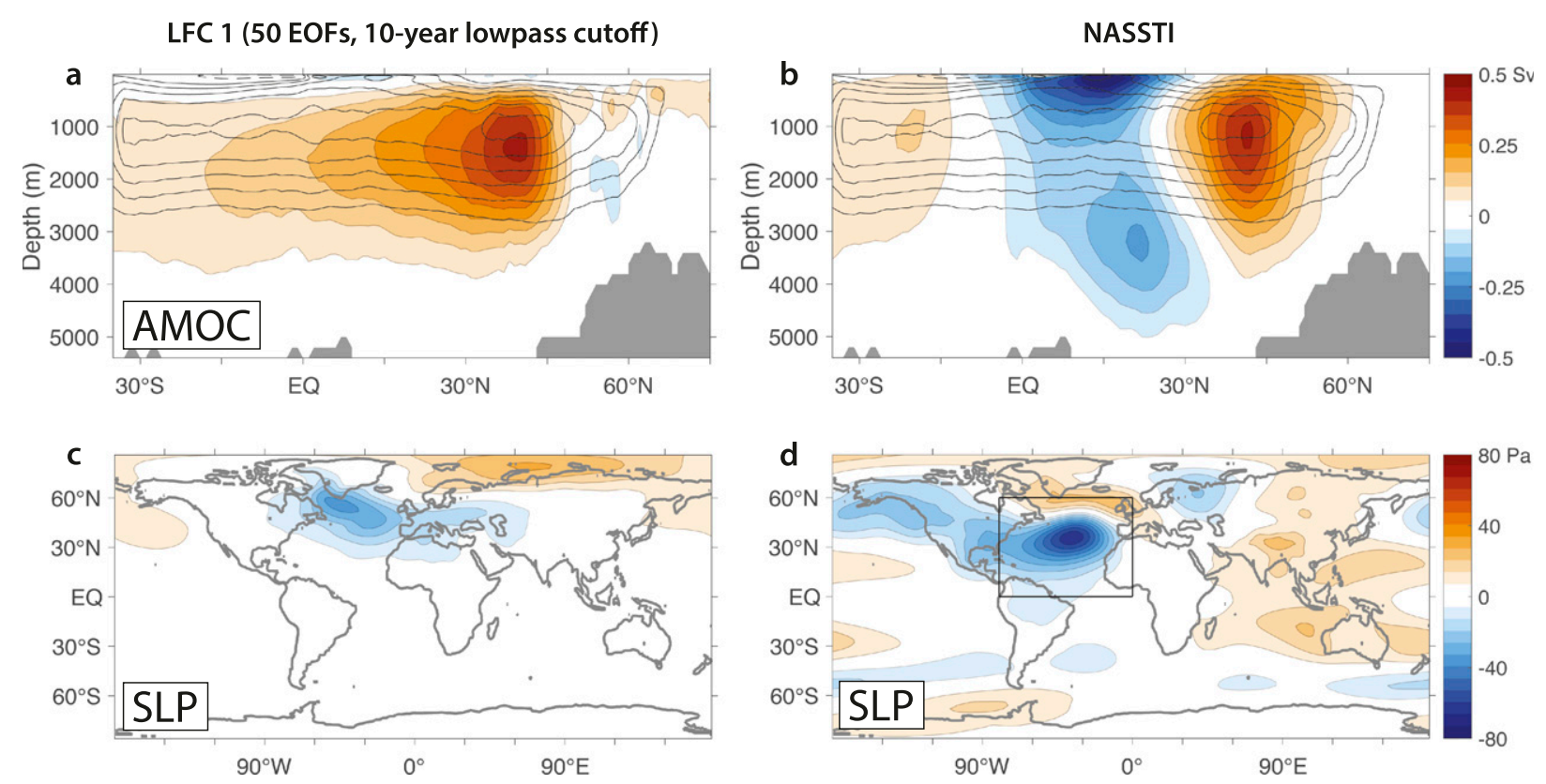

FIG. 4. Oceanic and atmospheric circulation anomalies associated with AMO in coupled climate models. Regression of AMOC streamfunction anomalies onto (a) LFC 1 and (b) NASSTI. Black contours show the climatological AMOC streamfunction (contour interval: 2 Sv). Regression of SLP anomalies onto (c) LFC 1 and (d) NASSTI. Averaging is done over the 16 models with AMOC data for (a) and (b) and all 26 models for (c) and (d); see Table 1. Circulation anomalies shown correspond to a one standard deviation anomaly in the respective index.

with a positive NAO anomaly would act to cool the ocean; they can only lead to warming of the North Atlantic if anomalous ocean heat flux convergence overwhelms the atmosphere-driven cooling.

NASSTI additionally shows a negative NAO anomaly in the year preceding and the year of maximum warming (Figs. 4d, 5d). This negative NAO anomaly reduces heat fluxes from the ocean into the atmosphere leading to basinwide warming, but also contributing to the weakening of AMOC. LFC 1 shows muted negative NAO anomalies around lag- 0 , because the associated circulation anomaly is not well aligned with the NAO SLP pattern (Figs. 4c, 6; from years -1 to 1 ). This weakly negative NAO anomaly persists for $\sim 25$ years (not shown) and eventually leads to a phase reversal of the AMO after 20-45 years ( $95 \%$ confidence interval), but correlations at these lag times are not statistically significant in general, so we do not discuss them further. Over the course of a subpolar North Atlantic warm event (as characterized by LFC 1), the atmospheric circulation evolves from a positive NAO anomaly that helps to strengthen AMOC to a basin-scale low pressure anomaly that helps to communicate the warming into the subtropics (Fig. 6). The interplay between NAO and AMOC illustrates the role of ocean-atmosphere dynamic coupling in AMO variability.

A summary schematic of the physics of the AMO in coupled climate models, as illuminated by LFCA, is shown in Fig. 7. In the growth phase of an AMO warm event (years -12 to -2 ; Fig. 7a), strong zonal winds over the North Atlantic (e.g., associated with stochastic NAO variability) lead to anomalous heat loss from the Labrador Sea, helping to trigger deep-water formation and strengthen AMOC. Because AMOC takes several years to respond to NAO heat flux anomalies (Delworth and Zeng 2016), even white noise NAO forcing would result in red noise AMOC variability extending out to multidecadal time scales (Hasselmann 1976). Ocean heat transport associated with AMOC overcompensates for the initial cooling and leads to warming of the subpolar North Atlantic.

During the peak phase of an AMO warm event (years -2 to 0; Fig. 7b), AMOC reaches its maximum strength and a low pressure cell forms over the subpolar gyre, helping to extend the warming to the east and south through warm air advection and reduced evaporative cooling. Heat flux anomalies into the ocean in the eastern North Atlantic $\left(30^{\circ}-65^{\circ} \mathrm{N}, 0^{\circ}-30^{\circ} \mathrm{W}\right.$; Figs. $\left.3 \mathrm{~d}, 2 \mathrm{c}\right)$ add buoyancy and contribute to subsequent AMOC weakening, helping to terminate the AMOC-driven warm event. The atmospheric response to the AMOC maximum simultaneously contributes to further North Atlantic warming and to the weakening of AMOC such that the maximum warming lags the AMOC maximum by two years.

Within a year of the maximum warming, AMOC and the North Atlantic atmospheric circulation have 

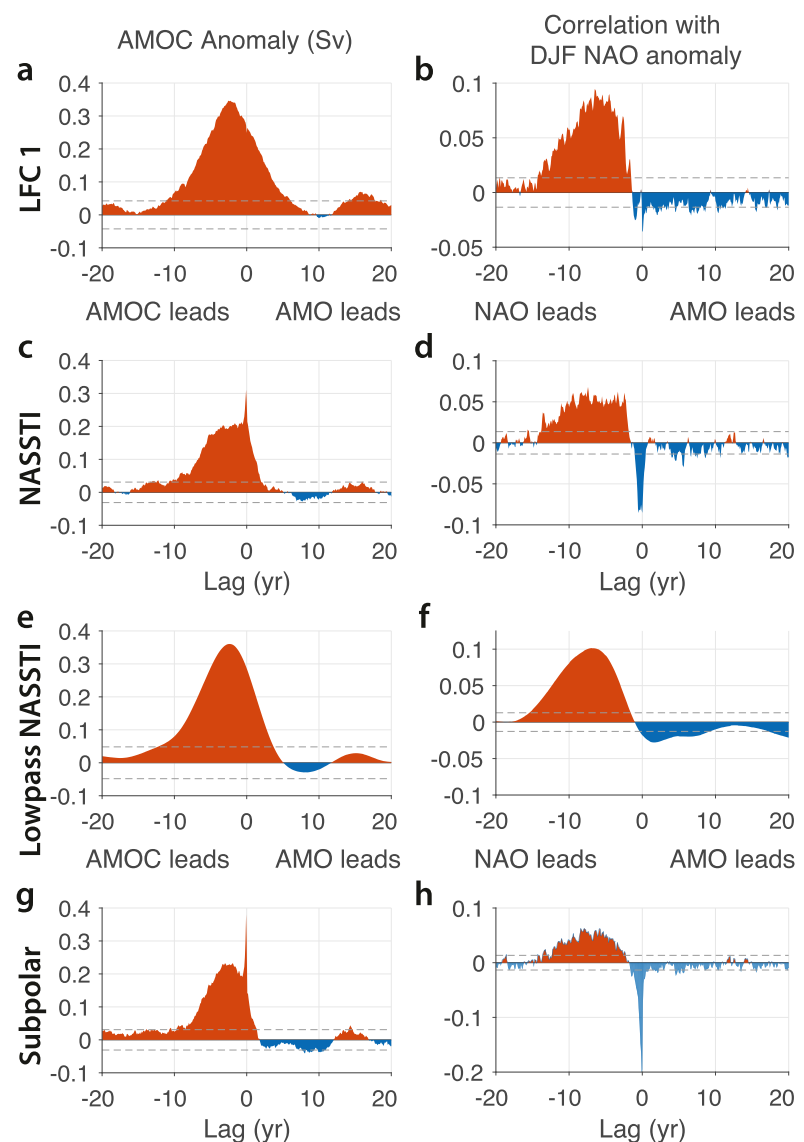

f

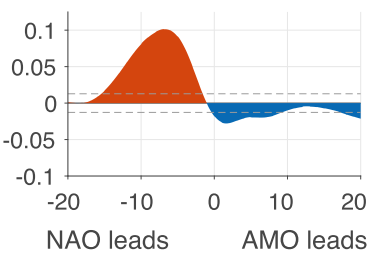

h

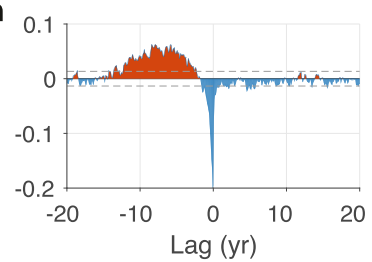

FIG. 5. Lead-lag relationships between AMO, AMOC, and NAO in coupled climate models. Lead-lag relationships between (left) AMOC and indices of Atlantic SST variability and (right) NAO and indices of Atlantic SST variability. AMOC is defined as the monthly AMOC streamfunction maximum north of the equator and below 500-m depth. AMOC anomalies (from the climatological seasonal cycle) are regressed onto monthly anomalies in the SST-based indices. Note that in the regression against NASSTI, the AMOC index mixes in gyre changes such as shown in Fig. 4b, which are responsible for the short-lived spike at lag-0. NAO is defined as the difference in the normalized SLP anomaly between Reykjavik and Lisbon (Hurrell 1995). The cross correlations between the SST-based indices and the NAO are computed for monthly anomalies, then averaged over DJF (based on the month of the SLP field). Dashed gray lines give the $95 \%$ significance levels based on phase randomization. Note that the correlations can be increased simply by low-pass filtering the NAO and AMO indices, but this removes some of the rich temporal information near lag- 0 without increasing the statistical significance.

returned to near their climatologies. The decay phase (years 0 to 10 ; Fig. $7 \mathrm{c}$ ) is characterized by warm temperatures decaying away through anomalous air-sea heat fluxes. This schematic synthesizes mechanistic understanding of the AMO growth phase (Delworth and Zeng 2016) with mechanistic understanding of AMO's influence on the tropical Atlantic (Yuan et al. 2016;
Brown et al. 2016) and elucidates the role of the atmospheric circulation response in driving buoyancy gain in the North Atlantic current, which helps to terminate AMO warm events. Note that these mechanisms also apply to AMO cold events (with opposite sign).

The NAO index is used for this mechanistic picture not because it provides the ideal AMOC perturbation but because it is a canonical index that explains a large fraction of the total atmospheric circulation variability over the North Atlantic (Hurrell 1995). Any perturbation that leads to heat loss from the subpolar North Atlantic should also spin up AMOC and lead to a delayed subpolar warming. Future work should consider how these mechanisms differ when Labrador Sea heat fluxes are driven by anthropogenic radiative forcing rather than stochastic atmospheric variability, as this could help to disentangle internal variability from forced responses in observed Atlantic temperatures.

\section{Indices of Atlantic multidecadal variability}

LFC 1 and NASSTI give two different statistical representations of processes contributing to multidecadal variability of Atlantic SSTs. LFC 1, by definition, has a higher ratio of low-frequency (i.e., multidecadal) to total variance than NASSTI. As a result, it has at least twice as much variance at 30-200-yr time scales and half as much at 2-6-yr time scales (Fig. 8a). Neither index has any strong spectral peaks in the multimodel mean, besides the peak at annual time scales in LFC 1 , which is a consequence of low-frequency AMOC-driven SST anomalies having the largest manifestation in wintertime temperatures. Despite their differences, LFC 1 is relatively coherent with NASSTI at low frequencies (Fig. 8b), meaning that they are capturing much of the same multidecadal variability. This coherence at low frequencies helps to explain why NASSTI still captures the lead-lag relationships with NAO and AMOC on long time scales (Figs. 5c,d).

On the time scales where they are coherent, LFC 1 leads NASSTI by about one year (Fig. 8c), suggesting that AMOC-driven low-frequency variability of the subpolar North Atlantic can lead to basinwide SST anomalies in the following year, likely because of its impact on the subtropical atmospheric circulation and subtropical low clouds (Yuan et al. 2016; Brown et al. 2016). In fact, at lead times of $1-10$ years, LFC 1 is a better predictor of NASSTI than NASSTI itself (Fig. 8d). This makes a strong case that LFC 1 would be a useful index for decadal predictions. It is a crucial point that processes in the subpolar North Atlantic lead to multidecadal variability throughout the Atlantic, since many of the impacts of the AMO are associated with SST anomalies at lower latitudes (Ruprich-Robert et al. 2017). 

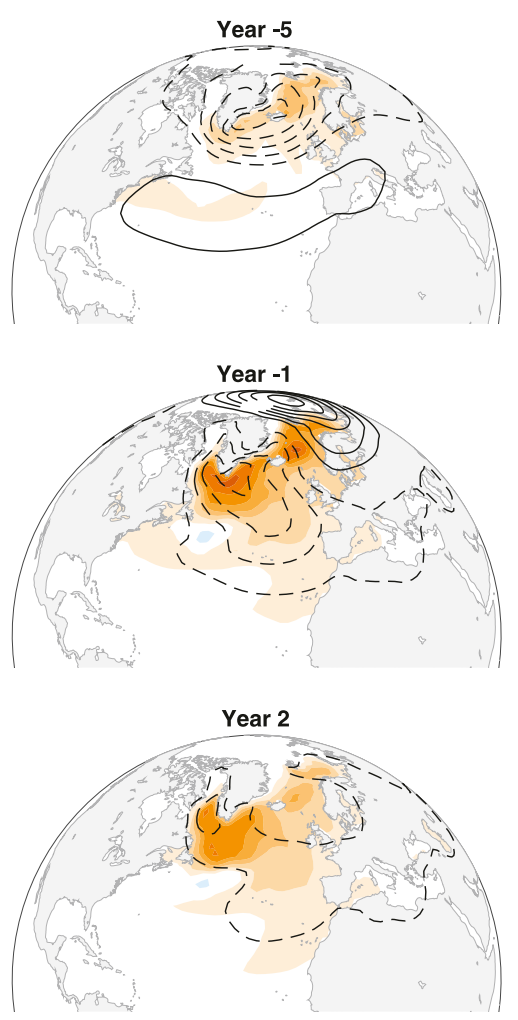
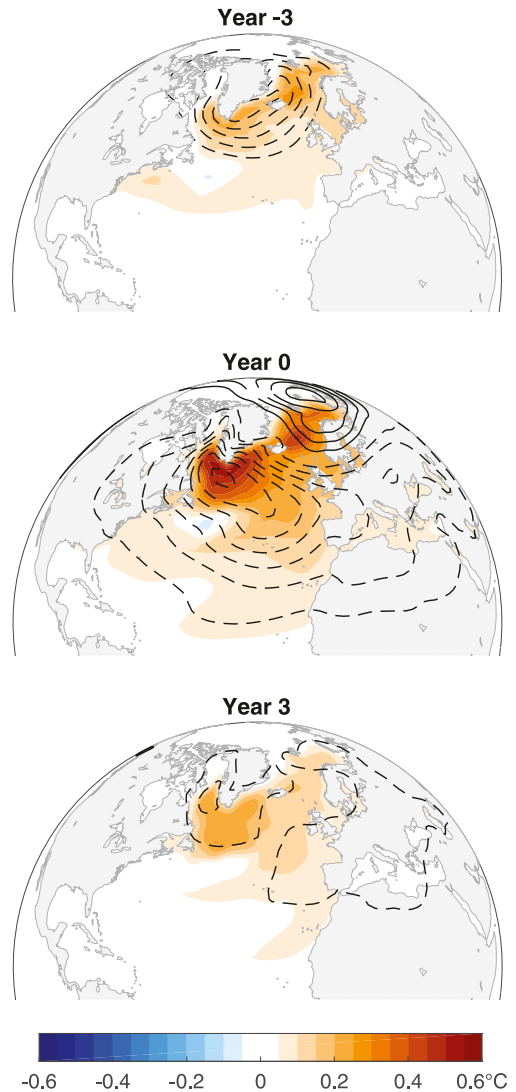
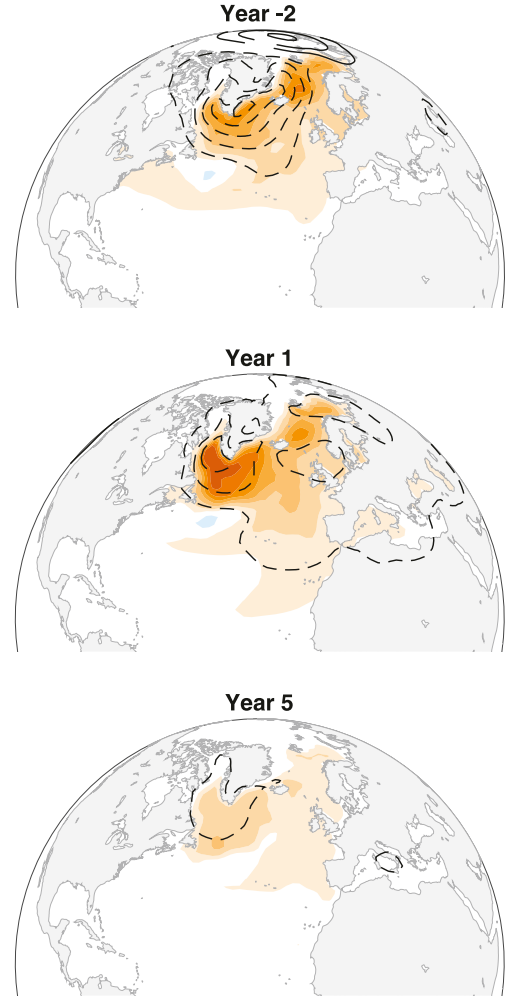

FIG. 6. AMO evolution. Regressions of SST (shading) and SLP (contours; contour interval 5 Pa; dashed negative) on LFC 1 for various lead and lag times. Year 0 is the year of maximum warming as characterized by LFC 1 . We focus on the 10 years surrounding a maximum in LFC 1, because the statistical significance of these regressions is small for longer lead-lag times (i.e., even though LFC 1 evolves on multidecadal time scales, it is only predictable on decadal time scales).

An alternate index of Atlantic variability, based on the monthly SST anomaly averaged over the subpolar North Atlantic $\left(40^{\circ}-60^{\circ} \mathrm{N}, 20^{\circ}-60^{\circ} \mathrm{W}\right.$; Fig. 9a), also obscures the role of AMOC in AMO variability by mixing it with (high frequency) atmosphere-driven warming of the subpolar gyre. This reduces its ratio of low-frequency to total variance (such that it is equal to that of NASSTI), causes it to show a correlation with anomalous heat fluxes into the ocean at lag-0 (Fig. 9b), and obscures its covariance with AMOC (Fig. 9c). The regression of SLP onto the subpolar SST index shows a negative NAO anomaly (Fig. 9d). This is associated with heat gain in the Labrador Sea and the eastern North Atlantic (Fig. 9b), which contributes to AMOC weakening. Variability of the subpolar SST index is associated with atmospheric variability that drives local warming through air-sea fluxes, but these heat flux anomalies act to weaken AMOC, resulting in short-lived warm events. This is evident in the rapid decrease in AMOC following the strong negative NAO anomaly (Figs. 5g,h). Even though the subpolar SST index focuses on the same region of SST variability as LFC 1, it obscures the mechanisms that are important on decadal and longer time scales. This illustrates how LFCA goes beyond simply identifying the relevant region of Atlantic multidecadal variability by providing an improved AMO index that is useful in diagnosing the associated physical mechanisms.

Analyzing physical mechanisms based on a 10-yr lowpass filtered NASSTI, similar to what has been done by a number of other studies (Brown et al. 2016; Zhang et al. 2016; O'Reilly et al. 2016), recovers some of the conclusions as we have with LFCA (compare Fig. 10 with Figs. 2 and 4; Fig. 5e with Fig. 5a; and Fig. 5f with Fig. 5b), but makes strong assumptions about the spatial pattern of AMO SST anomalies and shows a different relationship between atmospheric circulations and the AMO. The SST pattern associated with the low-pass filtered NASSTI resembles that of NASSTI (by construction), but with weight shifted toward the subpolar part of the pattern (Fig. 10a, cf. Fig. 2b). The basinwide low pressure anomaly that is characteristic of AMOCdriven subpolar warming does not show up in the SLP 

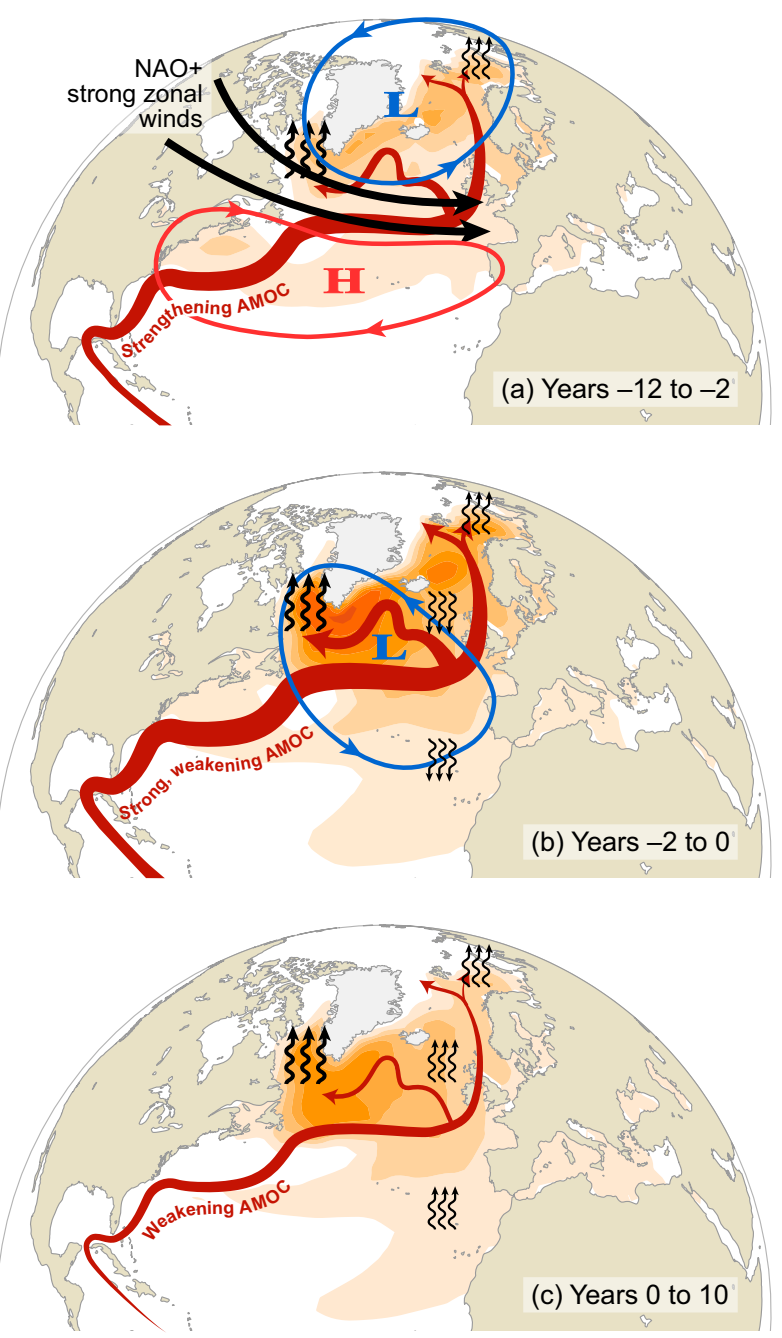

FIG. 7. Schematic evolution of an AMO warm event. Summary of the atmospheric and oceanic anomalies during the (a) growth, (b) peak, and (c) decay phases of an AMO warm event. Orange shading shows an SST anomaly characteristic of each stage (taken from years $-5,-1$, and 3 in Fig. 6). Blue and red contours indicate low and high pressure anomalies, respectively. Black arrows indicate strong zonal winds during the growth stage. Upward squiggly arrows indicate anomalous heat fluxes (including radiation) from the ocean into the atmosphere; downward indicate fluxes from the atmosphere into the ocean. The dark red arrow shows the path of the Gulf Stream and North Atlantic Drift; its width corresponds to the magnitude of the AMOC anomaly in each phase of the AMO. Note that the heat flux anomalies in the eastern North Atlantic (southeast of Iceland) and in the subtropical North Atlantic change signs between (b) the peak phase and (c) the decay phase, indicating that SST anomalies are driven by the atmosphere in this region (while being driven by the ocean elsewhere).

regression on the low-pass filtered NASSTI because the filtering mixes together the positive NAO anomaly that precedes subpolar warming with the basinwide low pressure that follows, resulting in a weak SLP anomaly at lag-0 (Fig. 10d, cf. Fig. 4c). Similarly, the filtering mixes together heat flux anomalies that precede the warming with those that follow such that it is difficult to distinguish atmosphere-driven and ocean-driven heat fluxes (Figs. 10b, 3). The advantage of LFCA in this context is that it highlights the regions and physical mechanisms relevant to multidecadal variability without explicitly lowpass filtering the data, which can mix together processes that precede warm events with those that follow (Cane et al. 2017), making inferences about causality difficult.

Other studies have used low-pass filtered subpolar SST anomalies (Zhang 2017) or low-pass filtered AMOC streamfunction anomalies (Yan et al. 2018) as indices of Atlantic multidecadal variability. Such indices recover many of the same mechanistic insights as we have with LFCA but remove all information about subdecadal variations. LFCA uses information about the spatiotemporal covariance of subdecadal variability in order to optimally filter it out, obtaining a monthly resolved index of multidecadal variability. Such an index is useful for determining the impact of subdecadal variations on multidecadal SST variability (e.g., variations in the NAO or in northeast Atlantic heat fluxes; Fig. 5b and Fig. 3, respectively). That is not to say this is the only way to get this information. For example, Guan and Nigam (2009) have separated off a subpolar component of the AMO using extended EOF analysis. However, for the purposes of defining indices of multidecadal variability, one clear advantage of LFCA is that it identifies the anomaly pattern with the highest possible ratio of multidecadal "signal" to interdecadal "noise."

\section{Slab-ocean models}

Our results help to reconcile studies suggesting that the AMO in slab-ocean models (in which ocean circulation cannot vary) is similar to that in comprehensive models and observations (Clement et al. 2015; Cane et al. 2017), with literature showing the importance of AMOC variability for AMO (Delworth et al. 1993; Delworth and Mann 2000; Latif et al. 2004; Knight et al. 2005; Medhaug and Furevik 2011; Wang and Zhang 2013; Zhang and Wang 2013; MacMartin et al. 2013; Ba et al. 2014; O'Reilly et al. 2016; Kim et al. 2018; Garuba et al. 2018). Atlantic basin mean warming (i.e., a positive NASSTI anomaly) is preceded by anomalous heat fluxes from the atmosphere into the ocean, showing that NASSTI is primarily driven directly by atmospheric forcing (and could thus be simulated by slab-ocean models). However, lower-frequency SST variability in the subpolar North Atlantic is primarily driven by ocean circulation changes that sustain anomalous heat transport into the subpolar North Atlantic. These ocean circulation changes are partially a response to prior 


\section{a}

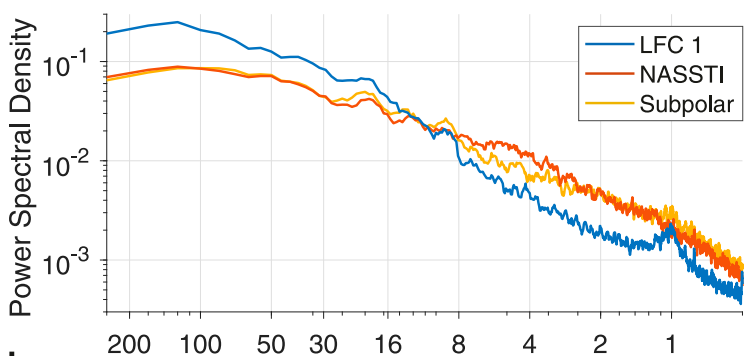

b

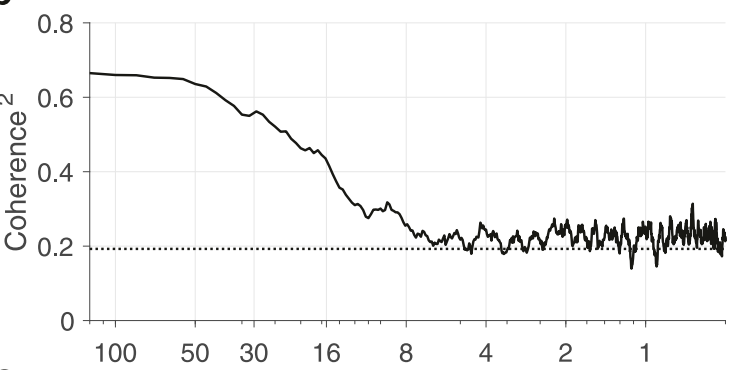

C

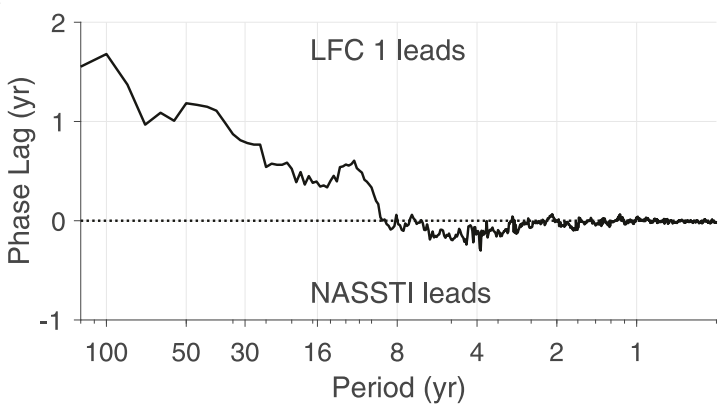

d

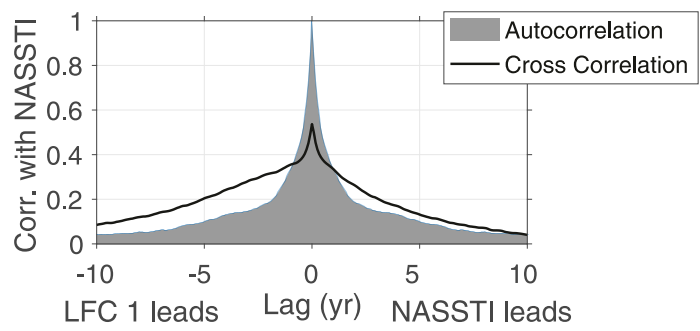

FIG. 8. Time scales of Atlantic SST variability. (a) Multimodel mean power spectrum of LFC 1 , NASSTI, and the subpolar $\left(40^{\circ}-\right.$ $60^{\circ} \mathrm{N}, 20^{\circ}-60^{\circ} \mathrm{W}$ ) SST index. (b) Multimodel mean squared coherence of LFC 1 and NASSTI. The dashed line gives the $95 \%$ significance level (0.19). (c) Phase lag associated with the coherence spectrum in (b). Positive phase lags indicate the extent to which LFC 1 leads NASSTI. (d) Lead-lag correlation between LFC 1 and NASSTI (black line). The gray shading shows the NASSTI autocorrelation for comparison.

atmospheric forcing, but are driven by anomalous surface heat fluxes from the ocean to the atmosphere (which by themselves would act to cool the subpolar North Atlantic). Both processes contribute to Atlantic SST variability, albeit on different time scales and in different geographic regions. The coupled atmosphere-ocean variability of the subpolar North Atlantic explains more than twice as much multidecadal SST variance as NASSTI, illustrating the importance of dynamic oceanatmosphere coupling in Atlantic multidecadal variability.

As a final test of these conclusions, we run our analysis on a preindustrial control simulation of a slab-ocean model, wherein SSTs are allowed to respond thermodynamically to atmospheric fluxes but no ocean dynamics or heat transport changes are resolved. We use a 901-yr simulation of the CAM5 atmospheric general circulation model coupled to a slab-ocean (CESM1 in slab-ocean mode) and run with fixed preindustrial (year 1850) forcing. This simulation was run as part of the Community Earth System Model (CESM) Large Ensemble project (Kay et al. 2015). The leading LFP of Atlantic SSTs in the slab-ocean model shows warming in the subpolar North Atlantic, similar to the fully coupled models (Fig. 11a). Its ratio of low-frequency to total variance is $r=0.46$, smaller than but comparable to that in the corresponding coupled model (CESM1-BGC; $r=0.59$ ). However, a slab-ocean model cannot have anomalous heat fluxes out of the ocean preceding positive SST anomalies, because there is no ocean heat flux convergence to sustain this heat loss. Indeed, the lead-lag regression of subpolar heat flux anomalies on the slab-ocean LFC 1 shows anomalous heat fluxes into the ocean immediately before a warm event and out of the ocean immediately after (inset in Fig. 11b), indicating that the SST variability is atmosphere driven, as it must be in the absence of ocean dynamics.

Heat flux anomalies into the subpolar ocean in the years preceding a slab-ocean warm event are associated with large negative NAO anomalies (Fig. 12b), in contrast to the positive NAO anomalies that precede warm events in coupled models (Fig. 12a). The lead-lag correlations of the NAO and AMO (as characterized by LFC 1) have opposite signs between coupled and slab-ocean models at most lead times. This raises the question: Can we use this to distinguish which mechanism applies in observations? We calculate NAO over the period 1900-2014 from the NCAR Twentieth Century Reanalysis (Compo et al. 2011), and compute its lead-lag correlation with the AMO-like LFC 2 from the ERSST analysis. This analysis shows positive NAO anomalies from 30 to 5 years before the subpolar Atlantic warming and negative NAO anomalies in the decades following (Fig. 12c). This is qualitatively similar to the lead-lag relationship between NAO and AMO in the coupled models, albeit larger in magnitude and on longer time scales. It is inconsistent with the lead-lag relationship between NAO and AMO in slab-ocean models. In agreement with other recent studies (Zhang et al. 2016; O'Reilly et al. 2016), these results suggest that 

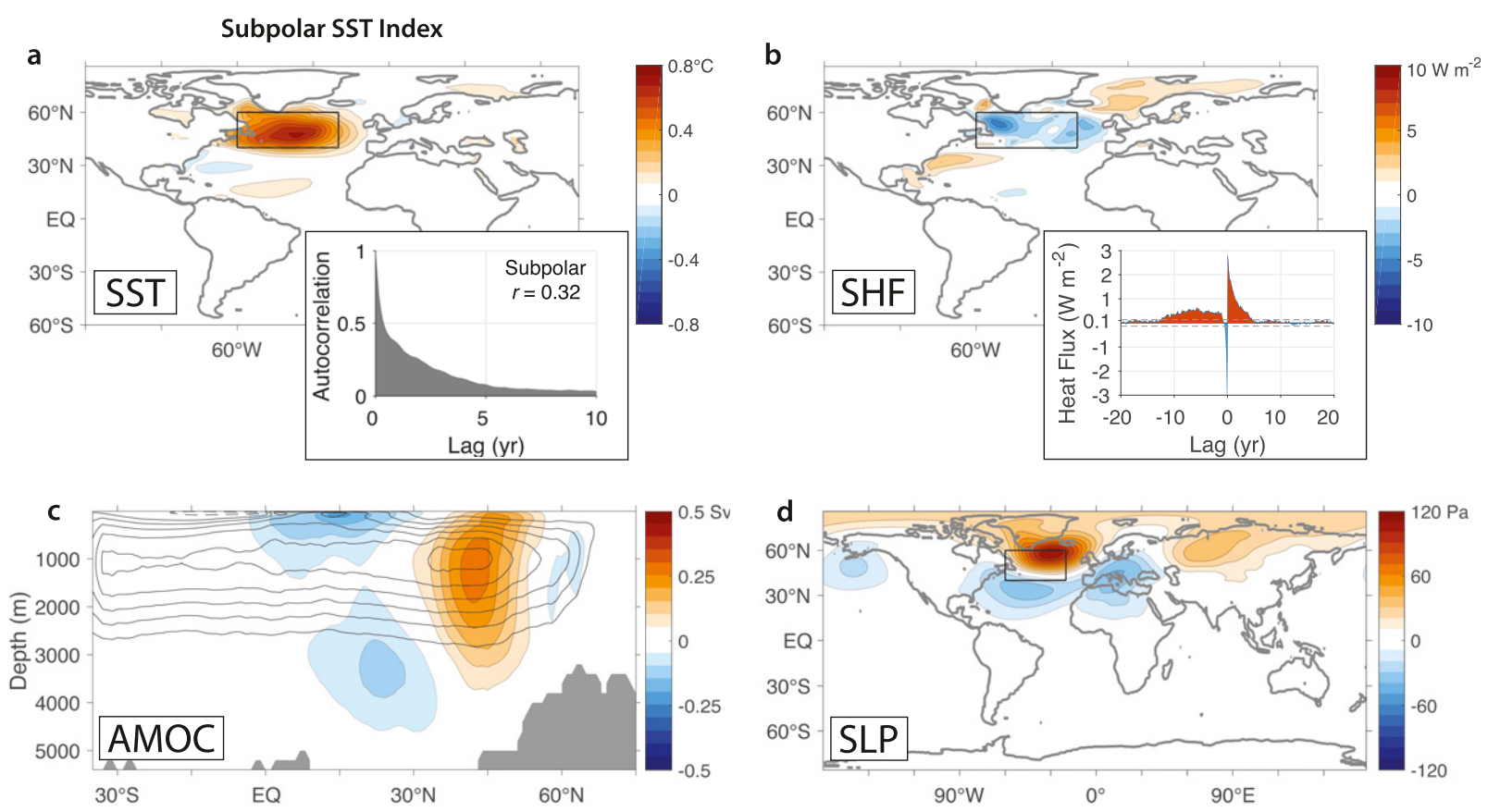

FIG. 9. Subpolar SST index. (a) SST pattern associated with an SST index based on the average SST anomaly over the subpolar box shown. The autocorrelation of the index is shown in the inset. (b) Net upward surface heat flux (SHF) anomalies associated with a one standard deviation anomaly in the subpolar SST index. The inset shows the lead-lag regression of heat flux anomalies (averaged over the subpolar box) onto the subpolar SST index. Lag-0 is the time where the SST pattern is maximum; positive lags indicate heat flux anomalies that lag the subpolar SST index. Dashed gray lines give the $95 \%$ significance levels based on phase randomization. (c) AMOC streamfunction anomaly associated with a one standard deviation anomaly in the subpolar SST index. The AMOC streamfunction climatology is shown in black contours (contour interval: 2 Sv). (d) SLP anomaly associated with a one standard deviation anomaly in the subpolar SST index.

the mechanisms of Atlantic multidecadal variability in slab-ocean models are inconsistent with the mechanisms of Atlantic multidecadal variability in coupled models and observations.

\section{Discussion and conclusions}

Low-frequency component analysis (LFCA) identifies the spatial signature of multidecadal Atlantic SST variability focused in the subpolar North Atlantic. The corresponding index is highly correlated with the AMO as traditionally defined but has a much higher ratio of interdecadal to intradecadal variance. This allows us to identify which physical mechanisms are important at decadal and longer time scales, filtering out mechanisms that play a role at shorter time scales.

We find that AMO temperature anomalies in unforced coupled climate models are driven by ocean heat flux convergence in the subpolar North Atlantic, associated with anomalies in AMOC. Stochastic atmospheric variability, such as the NAO, is an important influence on the evolution of AMOC because of its influence on air-sea heat fluxes in the Labrador Sea. A positive NAO anomaly is associated with strengthened westerlies off eastern North America, increasing heat loss from the Labrador Sea and increasing the strength of AMOC. During the peak phase of the AMO, a basinwide low pressure anomaly develops in response to the warmer temperatures and helps to spread the warming to the east and south through wind-evaporative and cloud feedbacks. Consistent with previous modeling studies of the impact of extratropical Atlantic SST anomalies on atmospheric circulation (e.g., Hodson et al. 2010; Sun et al. 2015), this anomaly is weak and does not project strongly onto the NAO. However, by using a large multimodel ensemble, we are able to characterize a statistically significant low pressure anomaly over the North Atlantic and weakly negative NAO in the years during and following a warm subpolar SST anomaly (Figs. 5, 6). This atmospheric circulation anomaly helps to weaken AMOC and terminate the AMOC-driven warming by adding buoyancy in the eastern North Atlantic. This mechanistic picture of the AMO suggests that ocean circulation provides the main source of inertia in the climate system that sustains SST anomalies on long time scales. Ocean mixed 

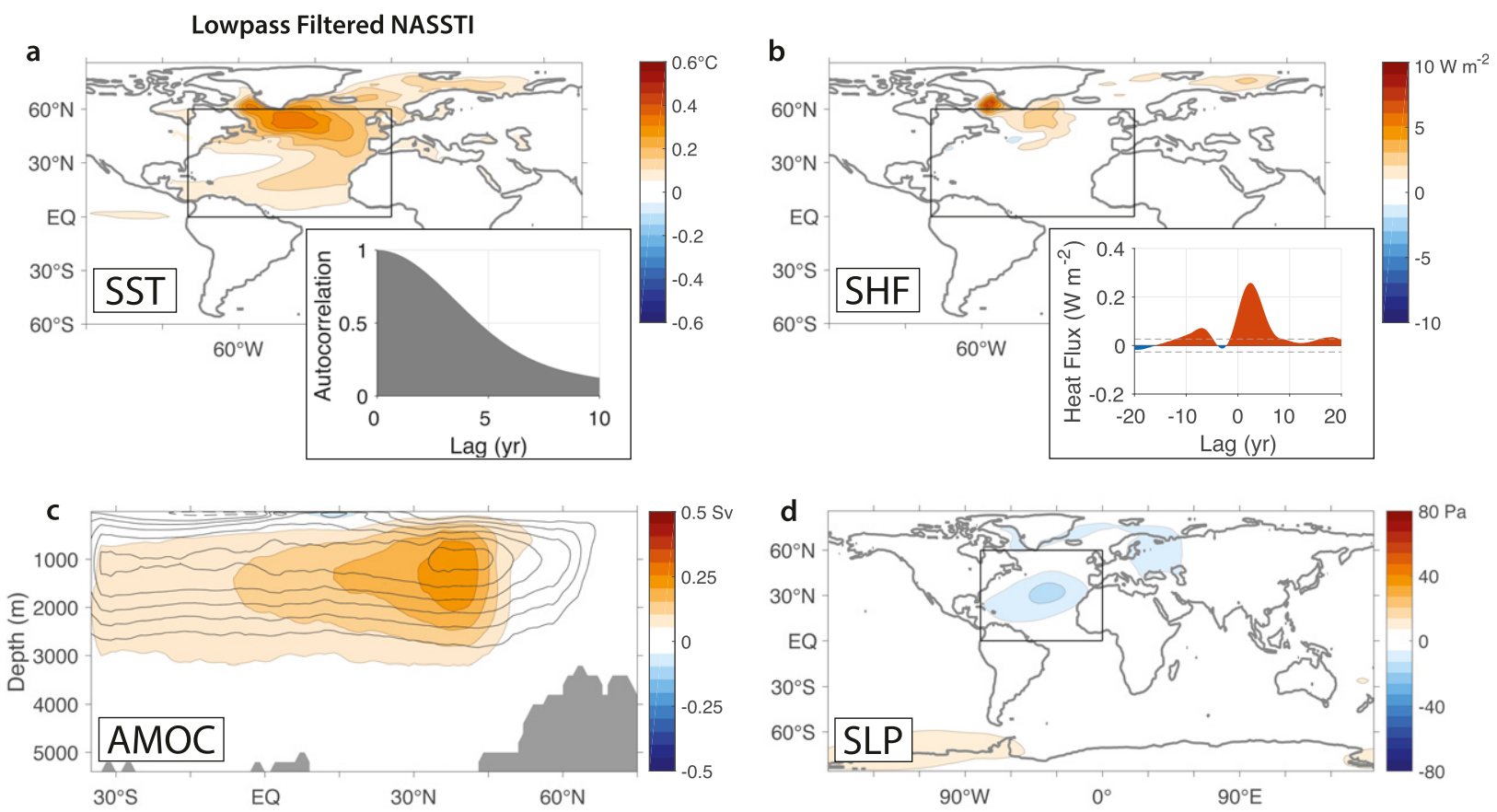

FIG. 10. Low-pass filtered NASSTI. (a) SST pattern associated with the 10-yr low-pass filtered NASSTI. The autocorrelation of the index is shown in the inset. (b) Net upward surface heat flux (SHF) anomalies associated with a one standard deviation anomaly in lowpass filtered NASSTI. The inset shows the lead-lag regression of heat flux anomalies (averaged over $0^{\circ}-60^{\circ} \mathrm{N}$ in the North Atlantic) onto low-pass filtered NASSTI. Lag-0 is the time when the SST pattern is maximum; positive lags indicate heat flux anomalies that lag low-pass filtered NASSTI. Dashed gray lines give the $95 \%$ significance levels based on phase randomization. (c) AMOC streamfunction anomaly associated with a one standard deviation anomaly in low-pass filtered NASSTI. The AMOC streamfunction climatology is shown in black contours (contour interval: $2 \mathrm{~Sv}$ ). (d) SLP anomaly associated with a one standard deviation anomaly in low-pass filtered NASSTI. The low-pass filtered NASSTI mixes together the positive NAO anomalies driving AMOC variability and the negative NAO anomalies helping to terminate AMOC-driven warm events such that it shows a weak overall SLP anomaly and obscures the role of oceanatmosphere dynamic coupling in AMO variability.

layer dynamics, which provides the source of inertia in the "slab-ocean" view of the AMO put forth by Clement et al. (2015) and Cane et al. (2017), is not the dominant mechanism in the North Atlantic at multidecadal time scales.

This study has focused on the mechanisms of unforced AMO variability in CMIP5 models. However, external forcing is thought to play a large role in observed AMO variability over the historical period (Booth et al. 2012; Tandon and Kushner 2015; Si and Hu 2017; Bellucci et al. 2017; Bellomo et al. 2018). Some of the insights about internal variability should also apply to forced changes because AMOC changes in response to forcing appear to be dominated by changes in surface heat fluxes, rather than changes in surface freshwater fluxes (Gregory et al. 2005). In unforced simulations, AMOC responds to NAO-driven heat flux anomalies in the Labrador Sea. In forced simulations, additional Labrador Sea heat fluxes due to greenhouse gas and aerosol forcing (including surface radiative fluxes) must be considered in the dynamics of AMOC and AMO.
The LFCA-based description of the AMO is largely consistent with other recent work showing that air-sea heat flux anomalies are ocean driven on decadal and longer time scales (Zhang et al. 2016; O'Reilly et al. 2016), that positive NAO anomalies can lead to AMOC strengthening and warming with a lag of several years (Sun et al. 2015; Delworth and Zeng 2016; Delworth et al. 2016, 2017), and that wind-evaporative and cloud feedbacks are important for extending warming into the tropical Atlantic (Yuan et al. 2016; Brown et al. 2016; Bellomo et al. 2016). The key benefit of LFCA in this context is that the derived AMO index is not lowpass filtered and can thus resolve rapid transitions and clarify the interactions between high-frequency atmospheric variability (i.e., NAO) and the slowly evolving ocean, including NAO interactions with AMOC (discussed in the main text) and NAO interactions with the Gulf Stream and gyre circulation (appendix B). Much of the previous work on the AMO is based on lead-lag regressions on low-pass filtered indices, which can mix together processes leading up to AMO events with those 

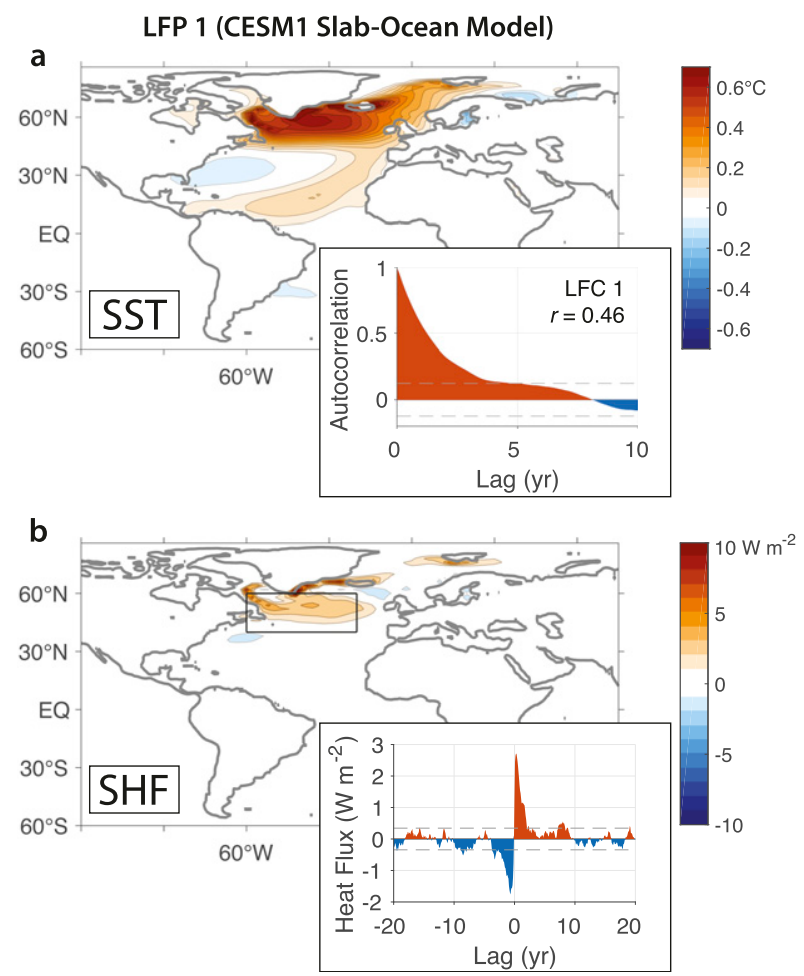

FIG. 11. Low-frequency component of slab-ocean simulation. (a) LFP 1 of Atlantic SSTs in a preindustrial control simulation with a slab-ocean version of CESM1. The inset shows the autocorrelation and low-frequency to total variance ratio $r$ of the associated LFC. (b) Regression of sea surface heat flux anomalies onto LFC 1 in the slab-ocean model. The map shows the lag-0 regression. The inset shows the lead-lag regression of heat flux anomalies averaged over the subpolar box. Lag-0 is the time when the SST pattern is maximum; positive lags indicate heat flux anomalies that lag LFC 1 . Dashed gray lines give the $95 \%$ significance levels based on phase randomization.

following and hide causal relationships (Cane et al. 2017). Using LFCA, we recover many of these conclusions while avoiding these pitfalls, adding confidence that dynamical coupling between atmospheric and oceanic circulations is fundamental to the dynamics of the AMO. Our analysis identifies the SST fingerprint of low-frequency $\mathrm{AMO} / \mathrm{AMOC}$ variability, which may be useful for ongoing efforts to monitor and predict the evolution of AMOC and the AMO.

Acknowledgments. We thank LuAnne Thompson, Clara Deser, and Tapio Schneider for providing helpful feedback on this work and Beth Tully for the creation of Fig. 7. R.C.J.W. and D.S.B. acknowledge support from the Tamaki Foundation. R.C.J.W. and D.L.H. acknowledge support from the National Science Foundation (Grant AGS-1549579). K.C.A acknowledges support from the National Science Foundation (Grant OCE-1523641). We acknowledge the World Climate Research Programme's Working Group on Coupled Modelling, which is responsible for CMIP, and we thank the climate modeling groups (listed in Table 1 of this paper) for producing and making available their model output. The MATLAB code for LFCA can be downloaded from https:/github. com/rcjwills/lfca.

\section{APPENDIX A}

\section{Differences across Models}

All results presented in the main text are a composite over 26 different CMIP5 models (Table 1). These different models show varying amplitudes and patterns of Atlantic multidecadal variability. In Figs. A1a and A1b, we plot the amplitude (relative to the ensemble mean) and low-frequency to total variance ratio of LFC 1 and NASSTI, respectively, in each model. The relative amplitude shows how much each model is weighted in the multimodel composites of the main text. Models that have above-average LFC 1 amplitude tend to have aboveaverage variance ratio as well, suggesting that the models with a low variance ratio (particularly GISS-E2-H, FGOALS-s2, BCC-CSM1.1, BNU-ESM, CCSM4, CanESM2, MRI-CGCM3, and NorESM1-M) simply do not display the

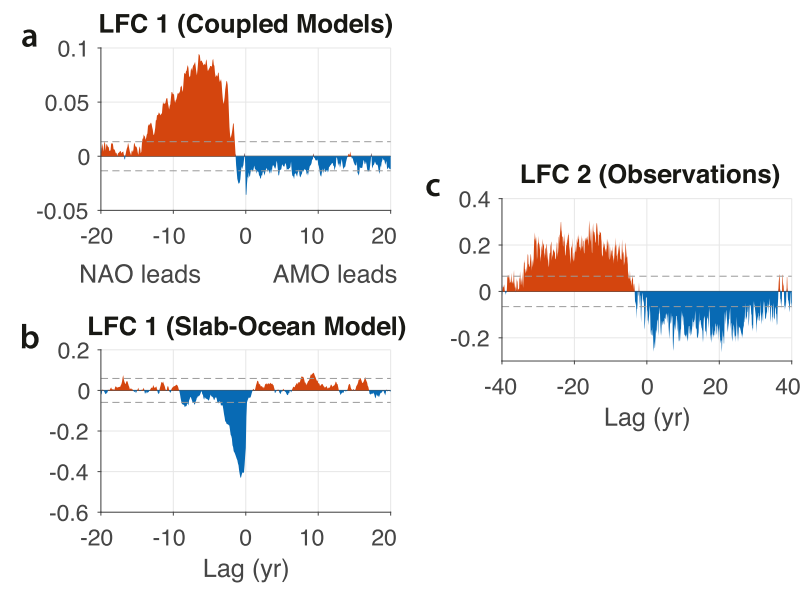

FIG. 12. Lead-lag correlation with NAO. Lead-lag relationship between DJF NAO anomaly and the AMO-like LFC in (a) fully coupled CMIP5 models, (b) the CESM1 slab-ocean simulation, and (c) observations. For the observational analysis, we take SLP from the NCAR Twentieth Century Reanalysis (Compo et al. 2011). NAO is defined as the difference in normalized SLP anomaly between Reykjavik and Lisbon (Hurrell 1995). The cross correlation between AMO and NAO is computed for monthly anomalies, then averaged over DJF (based on the month of the SLP field). Dashed gray lines give the $95 \%$ significance levels based on phase randomization [of LFC 1 for (a) and (b), of NAO for (c)]. Note the extended time axis in (c). 
a

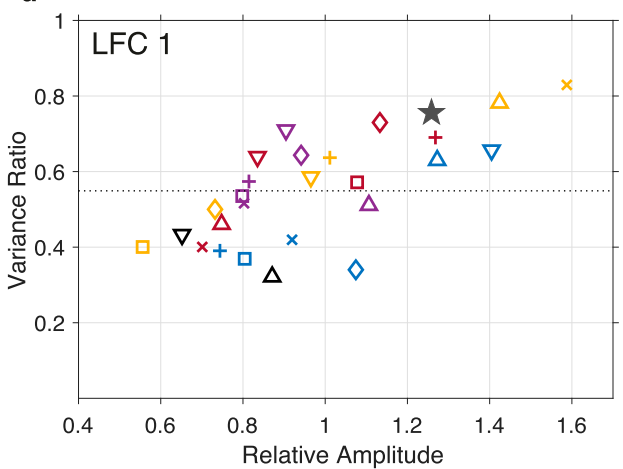

b

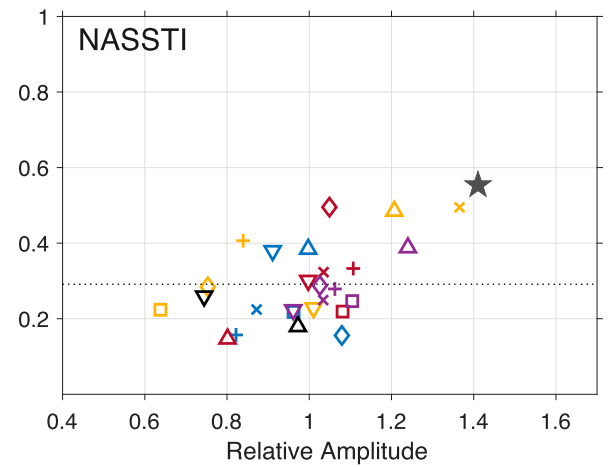

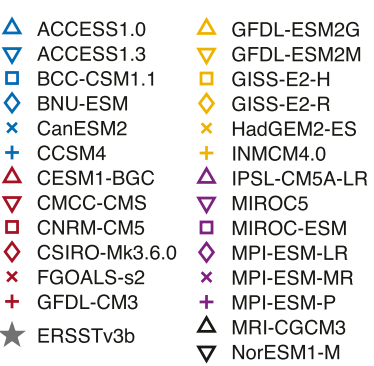

$\nabla$ ACCESS1.3 $\nabla$ GFDL-ESM2M

BCC-CSM1.1 $\square$ GISS-E2-H

$\diamond$ BNU-ESM $\diamond$ GISS-E2-R

$\times$ CanESM2 $\times$ HadGEM2-ES

+ INMCM4.0

$\nabla$ CMCC-CMS $\nabla$ MIROC5

口 CNRM-CM5 ㅁ MIROC-ESM

$\checkmark$ MPI-ESM-LR

$\begin{array}{ll}\times \text { FGOALS-S2 } & \times \text { MPI-ESM-M } \\ + \text { GFDL-CM3 } & + \text { MPI-ESM-P }\end{array}$

$\begin{aligned} \star \text { ERSSTV3b } & \Delta \text { MRI-CGCM3 } \\ & \nabla \text { NorESM1-M }\end{aligned}$

FIG. A1. AMO characteristics across models. Relative amplitude and low-frequency to total variance ratio of (a) LFC 1 and (b) NASSTI in each model. Since these indices have unit variance over the entire ensemble, the relative amplitude is the variance of the index in the data segment corresponding to an individual model (i.e., the ratio of variance within a model to the variance within the full ensemble). For ERSST, the relative amplitude is computed by comparing the amplitudes (spatial variance) of the patterns in Figs. 1 and 2, and the variance ratio is the ratio of low-frequency to total variance of the indices in Fig. 1c.

multidecadal variability associated with AMOC to as great of a degree. In all models, the variance ratio of LFC 1 is greater than the variance ratio of NASSTI. The amplitude and low-frequency to total variance ratio of the AMO-like LFC in ERSST are within, but at the upper end of, the range of values shown in the preindustrial ensemble. In terms of low-frequency to total variance ratio and amplitude, the models that show the AMO-like variability most similar to that within ERSST are ACCESS1.0, ACCESS1.3, CSIRO-Mk3.6.0, GFDL-CM3, GFDL-ESM2G, and HadGEM2-ES. The linearly detrended NASSTI has a much larger amplitude in ERSST than it does in the preindustrial simulations, but this is likely a consequence of mixing in part of the forced climate response.

We have also applied LFCA to each model separately to investigate the extent to which the individual-model LFPs resemble the ensemble-mean LFP 1. In most models, the LFC most correlated (in terms of temporal correlation) with LFC 1 from the multimodel ensemble analysis is one of the leading LFCs and shows a qualitatively similar pattern of warming to the ensemble-mean LFP 1, with localized warming in some region of the subpolar North Atlantic (Fig. A2, cf. Fig. 2a). In particular, ACCESS1 (two models), CMCC-CMS, CSIRO-Mk3.6.0, GFDL-CM3, GFDL-ESM2 (two models), GISS-E2-R, HadGEM2ES, INM-CM4.0, MIROC5, and MPI-ESM (three models) show patterns similar to the ensemble mean. A plausible reason for the differences between models is that they differ in their representations of the shape of the subpolar gyre and the geographic locations of deep water formation. Two models are omitted from Fig. A2 for space limitations: GISS-E2-H is similar to GISS-E2-R, but with a lower low-frequency to total variance ratio $(r=0.55)$; NorESM1-M shows substantial multidecadal variability, but it is mostly at smaller spatial scales than in other models, and none of it resembles the ensemble composite picture of AMO variability. Note that these two models (GISS-E2-H and NorESM1-M) contribute the least to the multimodel composite (Fig. A1).

\section{APPENDIX B}

\section{The Second Low-Frequency Component: Tripolar SST Anomalies Associated with the NAO}

The second LFP of monthly Atlantic SST anomalies (between $40^{\circ} \mathrm{S}$ and $75^{\circ} \mathrm{N}$ ) in the preindustrial ensemble shows a tripolar SST anomaly pattern in the highlatitude North Atlantic (Fig. B1a), with warming in the Gulf Stream, cooling in the subpolar gyre, and warming in the Norwegian seas. This is similar to the coupled ocean-atmosphere dynamics of Gulf Stream and gyre circulation variability studied by Taylor and Stephens (1998), Curry and McCartney (2001), Eden and Jung (2001), Sun et al. (2015), Gastineau and Frankignoul (2015), and Nigam et al. (2018), among others.

LFC 2 has a ratio of low-frequency to total variance $r=0.42$, compared to $r=0.60$ for LFC 1 . While LFCs 1 and 2 are uncorrelated at lag- 0 by definition, they have some lead-lag correlations, with negative LFC 1 anomalies tending to lead to positive LFC 2 anomalies, and positive LFC 2 anomalies tending to lead to positive LFC 1 anomalies (Fig. B1f). However, rather than indicating a causal relationship between LFCs 1 and 2, the cyclical nature of LFC 1/LFC 2 variability likely arises because they represent different time scales of the ocean's response to a common NAO forcing. There are positive NAO anomalies $0-6$ years before a maximum in LFC 2 (Fig. B1e) and 2-15 

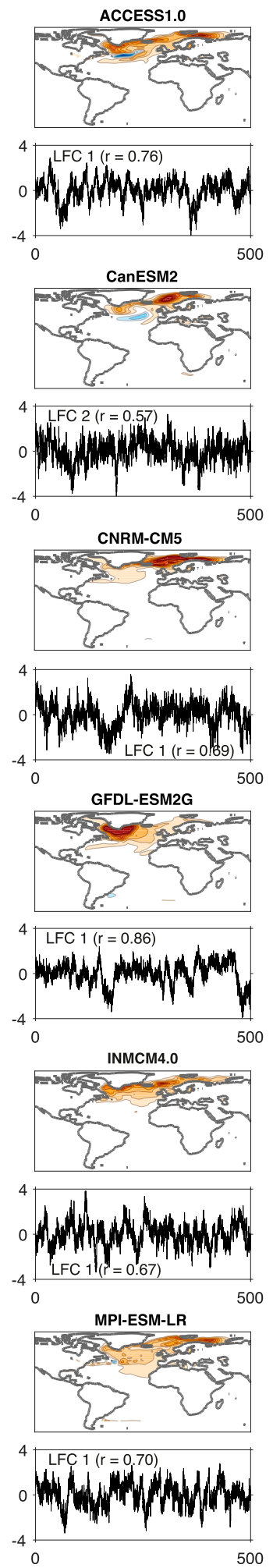
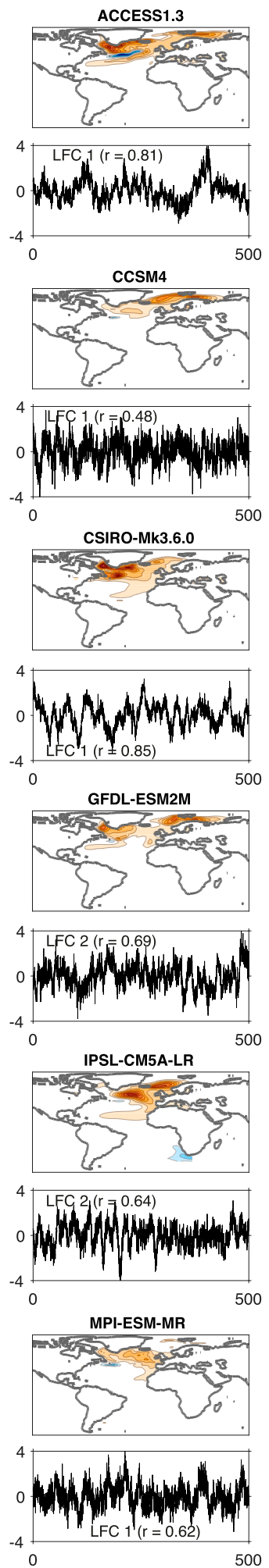
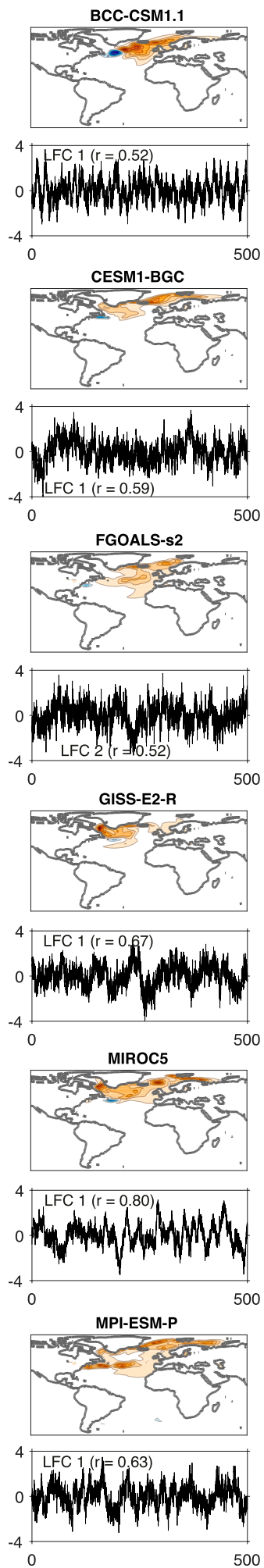
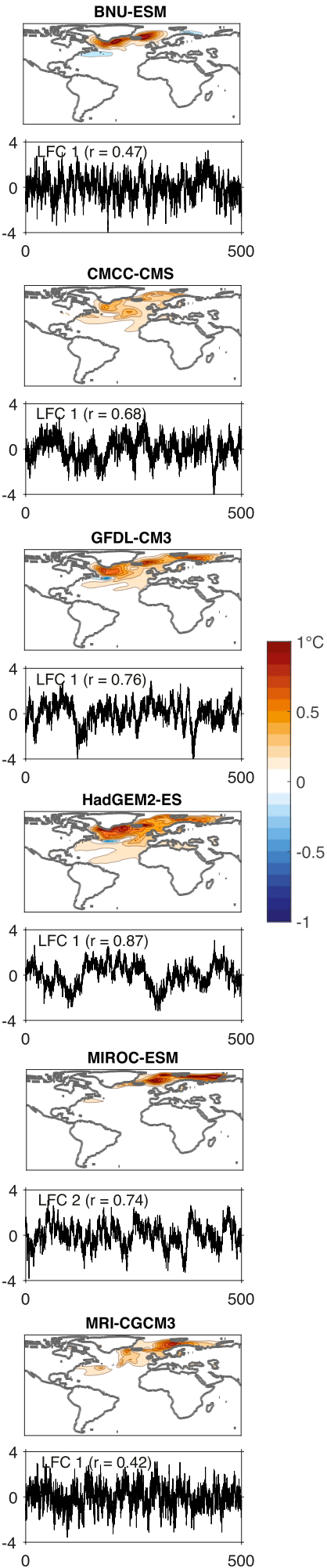

FIG. A2. Characterizing AMO in different models. The LFP with the highest pattern correlation with the full-ensemble LFP 1 (Fig. 2a) from LFCA of each model separately, and the evolution of its corresponding LFC (in units of standard deviation) vs model year. Note that the same LFC/LFP is identified if we choose it instead by its temporal correlation with the full-ensemble LFC 1. The low-frequency to total variance ratio $r$ is shown with each LFC. Note that some models (especially GFDL-ESM2G) have SST anomalies greater than $1^{\circ} \mathrm{C}$ that are saturated on the color scale. 

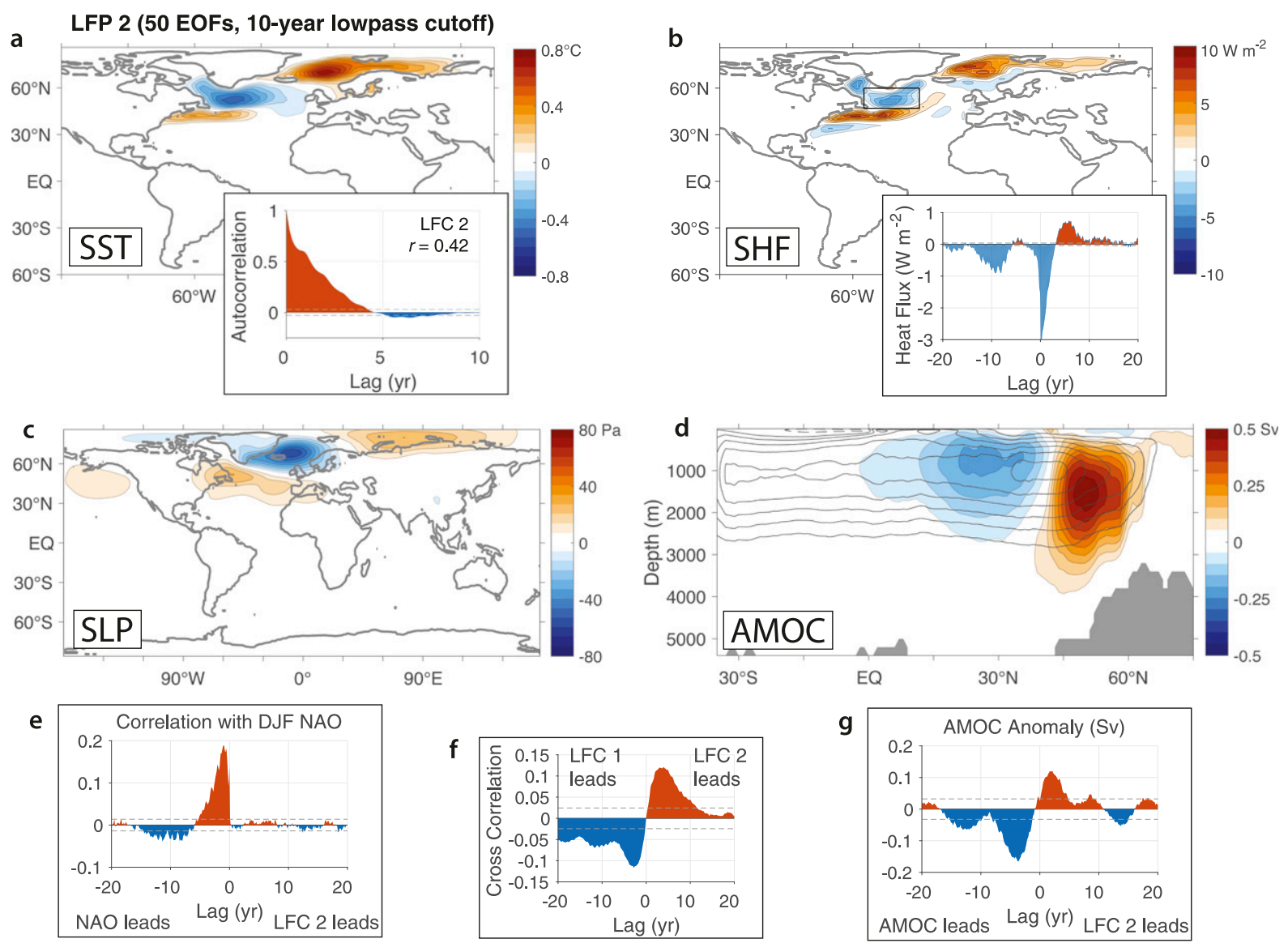

FIG. B1. Second LFC of Atlantic SSTs. (a) Spatial pattern of SST anomalies associated with a one standard deviation anomaly in LFC 2, computed over the CMIP5 preindustrial ensemble. The inset shows the LFC 2 autocorrelation. (b) Net upward surface heat flux (SHF) anomalies associated with a one standard deviation anomaly in LFC 2. The inset shows the lead-lag regression of heat flux anomalies (averaged over the box shown) onto LFC 2. (c) SLP anomaly associated with a one standard deviation anomaly in LFC 2. (d) AMOC streamfunction anomaly associated with a one standard deviation anomaly in LFC 2. The AMOC streamfunction climatology is shown in black contours (contour interval: $2 \mathrm{~Sv}$ ). (e) The lead-lag correlation between LFC 2 and the NAO, averaged over DJF. (f) The lead-lag correlation between LFCs 1 and 2. (g) The lead-lag regression of AMOC on LFC 2. NAO and AMOC are defined as in Fig. 5. Dashed gray lines give the $95 \%$ significance levels based on phase randomization.

years before a maximum in LFC 1 (Fig. 5b). Therefore, a persistent positive NAO anomaly would lead to first a positive LFC 2 anomaly, and then, after a lag, a positive LFC 1 anomaly.

As was the case for LFC 1, the net surface heat flux anomaly associated with LFC 2 indicates an active role of ocean heat transport, because warm temperatures are coincident with a net heat flux from the ocean to the atmosphere and vice versa (Fig. B1b). The lead-lag regression of subpolar gyre heat fluxes against LFC 2 shows heat flux into the ocean when the subpolar gyre is cold (lag-0), as well as anomalies at 10-yr lead times and 5-yr lag times that are associated with LFC 1 and AMOC (inset in Fig. B1b). The spatial scale and westward intensification of the SST and net surface heat flux anomalies suggest that this is a mode of variability in the ocean gyre circulations. However, there is also a high-latitude AMOC streamfunction anomaly associated with LFC 2 (Fig. B1d). It shows a latitudinal shift rather than a strengthening of AMOC and is therefore not well represented by the AMOC index (Fig. B1g). The positive AMOC anomaly associated with LFC 2 spans the latitude range beyond that of the hemispheric AMOC anomaly associated with LFC 1.

\section{REFERENCES}

Allen, M. R., and L. A. Smith, 1997: Optimal filtering in singular spectrum analysis. Phys. Lett., 234A, 419-428, https://doi.org/ 10.1016/S0375-9601(97)00559-8.

Ba, J., and Coauthors, 2014: A multi-model comparison of Atlantic multidecadal variability. Climate Dyn., 43, 2333-2348, https:// doi.org/10.1007/s00382-014-2056-1. 
Bellomo, K., A. C. Clement, L. N. Murphy, L. M. Polvani, and M. A. Cane, 2016: New observational evidence for a positive cloud feedback that amplifies the Atlantic multidecadal oscillation. Geophys. Res. Lett., 43, 9852-9859, https://doi.org/ 10.1002/2016GL069961.

— L. N. Murphy, M. A. Cane, A. C. Clement, and L. M. Polvani, 2018: Historical forcings as main drivers of the Atlantic multidecadal variability in the CESM Large Ensemble. Climate Dyn., 50, 3687-3698, https://doi.org/10.1007/s00382-017-3834-3.

Bellucci, A., A. Mariotti, and S. Gualdi, 2017: The role of forcings in the twentieth-century North Atlantic multidecadal variability: The 1940-75 North Atlantic cooling case study. J. Climate, 30, 7317-7337, https://doi.org/10.1175/JCLI-D-16-0301.1.

Berry, D. I., and E. C. Kent, 2009: A new air-sea interaction gridded dataset from ICOADS with uncertainty estimates. Bull. Amer. Meteor. Soc., 90, 645-656, https://doi.org/10.1175/ 2008BAMS2639.1.

Booth, B. B. B., N. J. Dunstone, P. R. Halloran, T. Andrews, and N. Bellouin, 2012: Aerosols implicated as a prime driver of twentieth-century North Atlantic climate variability. Nature, 484, 228-232, https://doi.org/10.1038/nature10946.

Brown, P. T., M. S. Lozier, R. Zhang, and W. Li, 2016: The necessity of cloud feedback for a basin-scale Atlantic multidecadal oscillation. Geophys. Res. Lett., 43, 3955-3963, https:// doi.org/10.1002/2016GL068303.

Buckley, M. W., R. M. Ponte, G. Forget, and P. Heimbach, 2014: Low-frequency SST and upper-ocean heat content variability in the North Atlantic. J. Climate, 27, 4996-5018, https://doi.org/ 10.1175/JCLI-D-13-00316.1.

Caesar, L., S. Rahmstorf, A. Robinson, G. Feulner, and V. Saba, 2018: Observed fingerprint of a weakening Atlantic Ocean overturning circulation. Nature, 556, 191-196, https://doi.org/ 10.1038/s41586-018-0006-5.

Cane, M. A., A. C. Clement, L. N. Murphy, and K. Bellomo, 2017: Low-pass filtering, heat flux, and Atlantic multidecadal variability. J. Climate, 30, 7529-7553, https://doi.org/10.1175/ JCLI-D-16-0810.1.

Chou, S.-H., E. Nelkin, J. Ardizzone, R. M. Atlas, and C.-L. Shie, 2003: Surface turbulent heat and momentum fluxes over global oceans based on the Goddard satellite retrievals, version 2 (GSSTF2). J. Climate, 16, 3256-3273, https://doi.org/ 10.1175/1520-0442(2003)016<3256:STHAMF $>2.0$.CO;2.

Clement, A., K. Bellomo, L. N. Murphy, M. A. Cane, T. Mauritsen, G. Rädel, and B. Stevens, 2015: The Atlantic multidecadal oscillation without a role for ocean circulation. Science, $\mathbf{3 5 0}$, 320-324, https://doi.org/10.1126/science.aab3980.

Compo, G. P., and Coauthors, 2011: The Twentieth Century Reanalysis Project. Quart. J. Roy. Meteor. Soc., 137, 1-28, https:// doi.org/10.1002/qj.776.

Cunningham, S. A., and Coauthors, 2007: Temporal variability of the Atlantic meridional overturning circulation at $26.5^{\circ} \mathrm{N}$. Science, 317, 935-938, https://doi.org/10.1126/science.1141304.

Curry, R. G., and M. S. McCartney, 2001: Ocean gyre circulation changes associated with the North Atlantic Oscillation. J. Phys. Oceanogr., 31, 3374-3400, https://doi.org/10.1175/ 1520-0485(2001)031<3374:OGCCAW>2.0.CO;2.

Day, J. J., J. C. Hargreaves, J. D. Annan, and A. Abe-Ouchi, 2012: Sources of multi-decadal variability in Arctic sea ice extent. Environ. Res. Lett., 7, 034011, https://doi.org/10.1088/1748-9326/ 7/3/034011

Delworth, T. L., and M. E. Mann, 2000: Observed and simulated multidecadal variability in the Northern Hemisphere. Climate Dyn., 16, 661-676, https://doi.org/10.1007/s003820000075.
— , and F. Zeng, 2016: The impact of the North Atlantic Oscillation on climate through its influence on the Atlantic meridional overturning circulation. J. Climate, 29, 941-962, https://doi.org/10.1175/JCLI-D-15-0396.1.

_, S. Manabe, and R. J. Stouffer, 1993: Interdecadal variations of the thermohaline circulation in a coupled ocean-atmosphere model. J. Climate, 6, 1993-2011, https://doi.org/10.1175/15200442(1993)006<1993:IVOTTC >2.0.CO;2.

_ , F. Zeng, G. A. Vecchi, X. Yang, L. Zhang, and R. Zhang, 2016: The North Atlantic Oscillation as a driver of rapid climate change in the Northern Hemisphere. Nat. Geosci., 9, 509-512, https://doi.org/10.1038/ngeo2738.

,-- L. L. Zhang, R. Zhang, G. A. Vecchi, and X. Yang, 2017: The central role of ocean dynamics in connecting the North Atlantic Oscillation to the extratropical component of the Atlantic multidecadal oscillation. J. Climate, 30, 3789-3805, https://doi.org/10.1175/JCLI-D-16-0358.1.

Ebisuzaki, W., 1997: A method to estimate the statistical significance of a correlation when the data are serially correlated. J. Climate, 10, 2147-2153, https://doi.org/10.1175/1520-0442(1997)010<2147: AMTETS $>2.0 . \mathrm{CO} ; 2$.

Eden, C., and T. Jung, 2001: North Atlantic interdecadal variability: Oceanic response to the North Atlantic Oscillation (1865-1997). J. Climate, 14, 676-691, https://doi.org/10.1175/ 1520-0442(2001)014<0676:NAIVOR > 2.0.CO;2.

Enfield, D. B., A. M. Mestas-Nuñez, and P. J. Trimble, 2001: The Atlantic multidecadal oscillation and its relation to rainfall and river flows in the continental U.S. Geophys. Res. Lett., 28, 2077-2080, https://doi.org/10.1029/2000GL012745.

Frankcombe, L. M., M. H. England, M. E. Mann, and B. A. Steinman, 2015: Separating internal variability from the externally forced climate response. J. Climate, 28, 8184-8202, https://doi.org/10.1175/JCLI-D-15-0069.1.

Garuba, O. A., J. Lu, H. A. Singh, F. Liu, and P. Rasch, 2018: On the relative roles of the atmosphere and ocean in the Atlantic multidecadal variability. Geophys. Res. Lett., 45, 9186-9196, https://doi.org/10.1029/2018GL078882.

Gastineau, G., and C. Frankignoul, 2015: Influence of the North Atlantic SST variability on the atmospheric circulation during the twentieth century. J. Climate, 28, 1396-1416, https://doi.org/ 10.1175/JCLI-D-14-00424.1.

Goldenberg, S. B., C. W. Landsea, A. M. Mestas-Nuñez, and W. M. Gray, 2001: The recent increase in Atlantic hurricane activity: Causes and implications. Science, 293, 474-479, https://doi.org/ 10.1126/science. 1060040.

Gray, W. M., 1990: Strong association between west African rainfall and U.S. landfall of intense hurricanes. Science, 249, 12511256, https://doi.org/10.1126/science.249.4974.1251.

Gregory, J. M., and Coauthors, 2005: A model intercomparison of changes in the Atlantic thermohaline circulation in response to increasing atmospheric $\mathrm{CO}_{2}$ concentration. Geophys. Res. Lett., 32, L12703, https://doi.org/10.1029/ 2005 GL023209.

Guan, B., and S. Nigam, 2009: Analysis of Atlantic SST variability factoring interbasin links and the secular trend: Clarified structure of the Atlantic multidecadal oscillation. J. Climate, 22, 4228-4240, https://doi.org/10.1175/2009JCLI2921.1.

Hasselmann, K., 1976: Stochastic climate models part I. Theory. Tellus, 28A, 473-485, https://doi.org/10.1111/j.2153-3490.1976. tb00696.x.

Hodson, D. L. R., R. T. Sutton, C. Cassou, N. Keenlyside, Y. Okumura, and T. Zhou, 2010: Climate impacts of recent multidecadal changes in Atlantic Ocean sea surface temperature: A multimodel 
comparison. Climate Dyn., 34, 1041-1058, https://doi.org/ 10.1007/s00382-009-0571-2.

Hoskins, B. J., and D. J. Karoly, 1981: The steady linear response of a spherical atmosphere to thermal and orographic forcing. J. Atmos. Sci., 38, 1179-1196, https://doi.org/10.1175/ 1520-0469(1981)038<1179:TSLROA > 2.0.CO;2.

Hurrell, J. W., 1995: Decadal trends in the North Atlantic Oscillation: Regional temperatures and precipitation. Science, $\mathbf{2 6 9}$, 676-678, https://doi.org/10.1126/science.269.5224.676.

Kay, J. E., and Coauthors, 2015: The Community Earth System Model (CESM) Large Ensemble Project: A community resource for studying climate change in the presence of internal climate variability. Bull. Amer. Meteor. Soc., 96, 1333-1349, https://doi.org/10.1175/BAMS-D-13-00255.1.

Kim, W. M., S. Yeager, P. Chang, and G. Danabasoglu, 2018: Lowfrequency North Atlantic climate variability in the Community Earth System Model Large Ensemble. J. Climate, 31, 787-813, https://doi.org/10.1175/JCLI-D-17-0193.1.

Knight, J. R., R. J. Allan, C. K. Folland, M. Vellinga, and M. E. Mann, 2005: A signature of persistent natural thermohaline circulation cycles in observed climate. Geophys. Res. Lett., 32, L20708, https://doi.org/10.1029/2005GL024233.

Latif, M., and Coauthors, 2004: Reconstructing, monitoring, and predicting multidecadal-scale changes in the North Atlantic thermohaline circulation with sea surface temperature. J. Climate, 17, 1605-1614, https://doi.org/10.1175/1520-0442(2004)017<1605: RMAPMC $>2.0 . \mathrm{CO} ; 2$.

MacMartin, D. G., E. Tziperman, and L. Zanna, 2013: Frequency domain multimodel analysis of the response of Atlantic meridional overturning circulation to surface forcing. J. Climate, 26, 8323-8340, https://doi.org/10.1175/JCLI-D-12-00717.1.

Mahajan, S., R. Zhang, and T. L. Delworth, 2011: Impact of the Atlantic meridional overturning circulation (AMOC) on Arctic surface air temperature and sea ice variability. J. Climate, 24, 6573-6581, https://doi.org/10.1175/2011JCLI4002.1.

McCabe, G. J., M. A. Palecki, and J. L. Betancourt, 2004: Pacific and Atlantic Ocean influences on multidecadal drought frequency in the United States. Proc. Natl. Acad. Sci. USA, 101, 4136-4141, https://doi.org/10.1073/pnas.0306738101.

Medhaug, I., and T. Furevik, 2011: North Atlantic 20th century multidecadal variability in coupled climate models: Sea surface temperature and ocean overturning circulation. Ocean Sci., 7, 389-404, https://doi.org/10.5194/os-7-389-2011.

Nigam, S., B. Guan, and A. Ruiz-Barradas, 2011: Key role of the Atlantic multidecadal oscillation in 20th century drought and wet periods over the Great Plains. Geophys. Res. Lett., 38, L16713, https://doi.org/10.1029/2011GL048650.

_ , A. Ruiz-Barradas, and L. Chafik, 2018: Gulf Stream excursions and sectional detachments generate the decadal pulses in the Atlantic multidecadal oscillation. J. Climate, 31, 28532870, https://doi.org/10.1175/JCLI-D-17-0010.1.

O'Reilly, C. H., M. Huber, T. Woollings, and L. Zanna, 2016: The signature of low-frequency oceanic forcing in the Atlantic multidecadal oscillation. Geophys. Res. Lett., 43, 2810-2818, https://doi.org/10.1002/2016GL067925.

Rahmstorf, S., J. E. Box, G. Feulner, M. E. Mann, A. Robinson, S. Rutherford, and E. J. Schaffernicht, 2015: Exceptional twentieth-century slowdown in Atlantic Ocean overturning circulation. Nat. Climate Change, 5, 475-480, https://doi.org/ 10.1038/nclimate2554; Corrigendum, 5, 956, https://doi.org/ 10.1038/nclimate2781.

Rayner, N. A., D. E. Parker, E. B. Horton, C. K. Folland, L. V. Alexander, D. P. Rowell, E. C. Kent, and A. Kaplan, 2003: Global analyses of sea surface temperature, sea ice, and night marine air temperature since the late nineteenth century. J. Geophys. Res., 108, 4407, https://doi.org/10.1029/2002JD002670.

Ruprich-Robert, Y., R. Msadek, F. Castruccio, S. Yeager, T. Delworth, and G. Danabasoglu, 2017: Assessing the climate impacts of the observed Atlantic multidecadal variability using the GFDL CM2. 1 and NCAR CESM1 global coupled models. J. Climate, 30, 2785-2810, https://doi.org/10.1175/JCLI-D-16-0127.1.

Schneider, T., and S. M. Griffies, 1999: A conceptual framework for predictability studies. J. Climate, 12, 3133-3155, https://doi.org/ 10.1175/1520-0442(1999)012<3133:ACFFPS > 2.0.CO;2.

, and I. M. Held, 2001: Discriminants of twentieth-century changes in Earth surface temperatures. J. Climate, 14, 249254, https://doi.org/10.1175/1520-0442(2001)014<0249: LDOTCC $>2.0 . \mathrm{CO} ; 2$.

Si, D., and A. Hu, 2017: Internally generated and externally forced multidecadal oceanic modes and their influence on the summer rainfall over East Asia. J. Climate, 30, 8299-8316, https:// doi.org/10.1175/JCLI-D-17-0065.1.

Smith, T. M., R. W. Reynolds, T. C. Peterson, and J. Lawrimore, 2008: Improvements to NOAA's historical merged landocean surface temperature analysis (1880-2006). J. Climate, 21, 2283-2296, https://doi.org/10.1175/2007JCLI2100.1.

Sun, C., J. Li, and F.-F. Jin, 2015: A delayed oscillator model for the quasi-periodic multidecadal variability of the NAO. Climate Dyn., 45, 2083-2099, https://doi.org/10.1007/ s00382-014-2459-z.

Sutton, R. T., and D. L. R. Hodson, 2005: Atlantic Ocean forcing of North American and European summer climate. Science, 309, 115-118, https://doi.org/10.1126/science.1109496.

Tandon, N. F., and P. J. Kushner, 2015: Does external forcing interfere with the AMOC's influence on North Atlantic sea surface temperature? J. Climate, 28, 6309-6323, https://doi.org/ 10.1175/JCLI-D-14-00664.1.

Taylor, A. H., and J. A. Stephens, 1998: The North Atlantic Oscillation and the latitude of the Gulf Stream. Tellus, 50A, 134 142, https://doi.org/10.3402/tellusa.v50i1.14517.

Taylor, K. E., R. J. Stouffer, and G. A. Meehl, 2012: An overview of CMIP5 and the experiment design. Bull. Amer. Meteor. Soc., 93, 485-498, https://doi.org/10.1175/BAMS-D-11-00094.1.

Ting, M., Y. Kushnir, R. Seager, and C. Li, 2009: Forced and internal twentieth-century SST trends in the North Atlantic. J. Climate, 22, 1469-1481, https://doi.org/10.1175/2008JCLI2561.1.

Trenberth, K. E., and D. J. Shea, 2006: Atlantic hurricanes and natural variability in 2005. Geophys. Res. Lett., 33, L12704, https://doi.org/10.1029/2006GL026894.

Venzke, S., M. R. Allen, R. T. Sutton, and D. P. Rowell, 1999: The atmospheric response over the North Atlantic to decadal changes in sea surface temperature. J. Climate, 12, 25622584, https://doi.org/10.1175/1520-0442(1999)012<2562: TAROTN $>2.0 . \mathrm{CO} ; 2$.

Wang, C., and L. Zhang, 2013: Multidecadal ocean temperature and salinity variability in the tropical North Atlantic: Linking with the AMO, AMOC, and subtropical cell. J. Climate, 26, 6137-6162, https://doi.org/10.1175/JCLI-D-12-00721.1.

Wills, R. C., T. Schneider, J. M. Wallace, D. S. Battisti, and D. L. Hartmann, 2018: Disentangling global warming, multidecadal variability, and El Niño in Pacific temperatures. Geophys. Res. Lett., 45, 2487-2496, https://doi.org/10.1002/2017GL076327.

Yan, X., R. Zhang, and T. R. Knutson, 2018: Underestimated AMOC variability and implications for AMV and predictability in CMIP models. Geophys. Res. Lett., 45, 4319-4328, https:// doi.org/10.1029/2018GL077378. 
Yeager, S. G., A. R. Karspeck, and G. Danabasoglu, 2015: Predicted slowdown in the rate of Atlantic sea ice loss. Geophys. Res. Lett., 42, 10 704-10 713, https://doi.org/10.1002/ 2015 GL065364.

Yu, L., and R. A. Weller, 2007: Objectively analyzed air-sea heat fluxes for the global ice-free oceans (1981-2005). Bull. Amer. Meteor. Soc., 88, 527-539, https://doi.org/10.1175/ BAMS-88-4-527.

Yuan, T., L. Oreopoulos, M. Zelinka, H. Yu, J. R. Norris, M. Chin, S. Platnick, and K. Meyer, 2016: Positive low cloud and dust feedbacks amplify tropical North Atlantic multidecadal oscillation. Geophys. Res. Lett., 43, 1349-1356, https://doi.org/ 10.1002/2016GL067679.

Zhang, J., and R. Zhang, 2015: On the evolution of Atlantic meridional overturning circulation fingerprint and implications for decadal predictability in the North Atlantic. Geophys. Res. Lett., 42, 5419-5426, https://doi.org/10.1002/2015GL064596.

Zhang, L., and C. Wang, 2013: Multidecadal North Atlantic sea surface temperature and Atlantic meridional overturning circulation variability in CMIP5 historical simulations. J. Geophys. Res. Oceans, 118, 5772-5791, https://doi.org/10.1002/ jgrc.20390.
Zhang, R., 2008: Coherent surface-subsurface fingerprint of the Atlantic meridional overturning circulation. Geophys. Res. Lett., 35, L20705, https://doi.org/10.1029/2008GL035463.

_ 2010: Latitudinal dependence of Atlantic meridional overturning circulation (AMOC) variations. Geophys. Res. Lett., 37, L16703, https://doi.org/10.1029/2010GL044474.

_ 2015: Mechanisms for low-frequency variability of summer Arctic sea ice extent. Proc. Natl. Acad. Sci. USA, 112, 45704575, https://doi.org/10.1073/pnas.1422296112.

- 2017: On the persistence and coherence of subpolar sea surface temperature and salinity anomalies associated with the Atlantic multidecadal variability. Geophys. Res. Lett., 44, 7865-7875, https://doi.org/10.1002/2017GL074342.

_ , and T. L. Delworth, 2006: Impact of Atlantic multidecadal oscillations on India/Sahel rainfall and Atlantic hurricanes. Geophys. Res. Lett., 33, L17712, https://doi.org/10.1029/ 2006GL026267.

R. Sutton, G. Danabasoglu, T. L. Delworth, W. M. Kim, J. Robson, and S. G. Yeager, 2016: Comment on "The Atlantic multidecadal oscillation without a role for ocean circulation." Science, 352, 1527-1527, https://doi.org/10.1126/ science.aaf1660. 